IZA DP No. 8840

\title{
Economic Shocks and Internal Migration
}

Joan Monras

February 2015 


\title{
Economic Shocks and Internal Migration
}

\author{
Joan Monras \\ Sciences Po, LIEPP \\ and IZA
}

\section{Discussion Paper No. 8840 \\ February 2015}

\author{
IZA \\ P.O. Box 7240 \\ 53072 Bonn \\ Germany \\ Phone: +49-228-3894-0 \\ Fax: +49-228-3894-180 \\ E-mail: iza@iza.org
}

\begin{abstract}
Any opinions expressed here are those of the author(s) and not those of IZA. Research published in this series may include views on policy, but the institute itself takes no institutional policy positions. The IZA research network is committed to the IZA Guiding Principles of Research Integrity.

The Institute for the Study of Labor (IZA) in Bonn is a local and virtual international research center and a place of communication between science, politics and business. IZA is an independent nonprofit organization supported by Deutsche Post Foundation. The center is associated with the University of Bonn and offers a stimulating research environment through its international network, workshops and conferences, data service, project support, research visits and doctoral program. IZA engages in (i) original and internationally competitive research in all fields of labor economics, (ii) development of policy concepts, and (iii) dissemination of research results and concepts to the interested public.
\end{abstract}

IZA Discussion Papers often represent preliminary work and are circulated to encourage discussion. Citation of such a paper should account for its provisional character. A revised version may be available directly from the author. 
IZA Discussion Paper No. 8840

February 2015

\section{ABSTRACT}

\section{Economic Shocks and Internal Migration*}

Previous literature shows that internal migration rates are strongly procyclical. This would seem to imply that geographic relocation does not help mitigate negative local economic shocks during recessions. This paper shows that this is not the case. I document that net inmigration rates decreased in areas more affected by the Great Recession. Using various IV strategies that rely on the importance of the construction sector and the indebtedness of households before the crisis, I conclude that internal migration might help to alleviate up to one third of the effects of the crisis on wages in the most affected locations. This is due to a disproportionate decrease in in-migration into those locations rather than an increase in outmigration. More generally, I show that differences in population growth rates across locations are mainly explained by differences in in-migration rates rather than in out-migration rates. I introduce a model to guide the empirical analysis and to quantify the spill-over effects caused by internal migration.

JEL Classification: J61, J20, J30, F22, J43, R23, R58

Keywords: internal migration, local labor demand shocks

Corresponding author:

Joan Monras

Economics Department and LIEPP

Sciences Po

28 , rue de Saint-Pères

75007, Paris

France

E-mail: joan.monras@sciencespo.fr

I would like to thank Don Davis, Eric Verhoogen and Bernard Salanié for guidance and encouragement and Jón Steinsson, Jesus Fernández-Huertas, Michel Serafinelli, Brian Kovak and seminar participants at IIES for useful comments and discussions. All errors are mine. 


\section{Introduction}

It is a common perception that "Americans have historically been an unusually mobile people, constantly seeking better economic conditions" (Moretti, 2012). We would, then, expect geographic relocation to be an important mechanism for American families to deal with periods of economic crisis. Is this the case?

US internal migration rates are strongly pro-cyclical (Saks and Wozniak, 2011). This could imply that (most) internal migrants move to take advantage of opportunities created during good economic years. It is less clear, however, whether internal migration also helps in bad times. The fact that aggregate migration rates decline in downturns might suggest that US families do not respond to negative economic shocks by moving to other parts of the country and that instead, families remain in their current location until the economy starts recovering. Is this true? Does this imply that spatial labor reallocation does not help mitigate negative local economic shocks in recessions?

In this paper, I use the Great Recession to study how migration decisions are shaped by the effects of the crisis at the local level, i.e. across metropolitan areas. Contrary to previous literaturesee Mian and Sufi (2013) and Molloy et al. (2011) - I show that geographic relocation was important in mitigating negative local economic shocks during the period 2006-2011. In particular, I show that the relocation mechanism is decreased in-migration rates into negatively hit locations, rather than increased out-migration from them.

To understand why reduced in-migration rates are important in mitigating the local effects during recessions it is, first, important to realize that while in many metropolitan areas the average net migration rate is close to 0 , the gross flows are always significantly higher since more than 3.5 percent of households change metropolitan areas in any given year ${ }^{1}$ Second, the decreased migration rates during recessions are, partly, a consequence of fewer people moving towards negatively shocked local labor markets. Third, this implies that the relevant counterfactual, i.e. what would have happened had the Great Recession not occurred, needs to take into account that more people would have moved to the negatively hit locations. This is crucial. In a closely related paper, Yagan (2014) shows how workers who suffered larger local shocks in 2006 still had worse outcomes through 2011, even if they relocated. He takes this as evidence that internal relocation does little to mitigate the negative consequences of local shocks. My results show that fewer workers moved into the locations most affected by the Great Recession. Had they done so, the wage and employment effects would have been even worse $2^{2}$ Adding this new element gives a more positive picture of the

\footnotetext{
${ }^{1}$ More generally, as computed in Molloy et al. (2011), around 1.5 percent of the population moves between Census regions, 1.3 percent move across states within these regions and around 3 percent move across counties within state. These numbers are obviously consistent with the reported migration rates across metropolitan areas.

${ }^{2}$ In Monras (2013) I show how the local labor demand elasticity is around -1, using the unexpected inflow of Mexicans resulting from the Mexican Peso Crisis of 1995. This is important since reduced in-migration mitigates the wage effects of the Great Recession only if the local labor demand elasticity is negative.
} 
ability of internal migration to smooth local shocks 3

In this paper, I show these results using two alternative strategies. My first strategy is to show that locations which had larger construction sectors before the crisis (measured by the share of employment in construction in 2000) suffered larger local economic shocks in 2008. These locations, in turn, saw their in-migration rates decline disproportionately.

My second strategy builds on the work by Mian and Suf (2013). They argue that the 2008 crisis lowered the consumption capacity of highly indebted households. This helps to explain the drop in consumption starting in 2008. Across the territory, the demand for tradables dropped uniformly, while the demand for non-tradables dropped more in highly indebted locations, precisely because non-tradable goods can only be consumed locally. This translates, as Mian and Sufi (2013) show, into declines in non-tradable employment in highly indebted locations, while it translates into uniform drops in employment in tradable sectors. Thus, locations that historically had larger employment shares in non-tradable employment and were highly indebted at the beginning saw sharper declines in per capita GDP and wages and higher increases in unemployment rates. This paper shows that this is associated with larger drops in the in-migration rates.

I find that a 1 percent decrease in wages leads to around a .30 percentage point decrease in the share of in-migrants at the local level. This helps to mitigate the shock that the crisis had on wages. If the elasticity of the local labor demand is equal to -1 (see Monras 2013) for an estimate of this order of magnitude) then the decrease in in-migration rates reduces the effect of the crisis on wages by around one third. This means that had these in-migrants moved into a city with an actual decrease of 1 percent in wages, the decrease would have been around 1.3 percent. I show these results in detail using a dynamic model of internal migration calibrated to the US economy. The model is able to capture not only the short-run response of internal migration and wages during the Great Recession, but also the full adjustment due to internal migration across local labor markets.

These results imply that geographic relocation (i.e. net migration) took place as a response to particularly strong negative local economic shocks during the Great Recession. In other words, the populations of more heavily hit locations grew less than before the crisis. This was a consequence of lower in-migration rates rather than out-migration.

Given these results, I then address the extent to which this mechanism can explain the growth and decline of cities or regions (Gabaix, 1999), (Eeckhout, 2004). To do so, I decompose the population growth rates of specific cohorts into in- and out- migration rates from all local labor markets 4 Using a number of different data sets and geographic definitions I obtain striking results. More than 90 percent of the variation in population growth rates across locations is accounted

\footnotetext{
${ }^{3}$ As emphasized in Topel (1986), the migrants that did not move to the negatively affected locations are themselves labor supply shocks that affect wages in locations less affected by the crisis.

${ }^{4}$ By "cohort", I refer here to all the people that I observe in either the American Community Survey, Current Population Survey or US Census for whom I know both their current location and their location one or five years before the survey takes place.
} 
for by variation in in-migration rates. This means that the growth and decline of cities, states or regions is mainly due to persistently high or low in-migration rates with little systematic differences in out-migration rates.

Several papers have looked at the response of local labor markets to negative local labor demand shocks. In a seminal contribution, Blanchard and Katz (1992) argue that locations affected by negative shocks experience permanent losses in employment, temporary increases in unemployment rates and temporary decreases in local wages. Their identification strategy does not distinguish between good and bad times, however. This has become an important issue because several papers have argued that during this last recession internal migration rates have not responded differently across multiple locations. Mian and Sufi (2013) argue that, if anything, populations increased (between 2007 and 2009) in highly indebted counties. This is obviously very puzzling for the spatial economic literature (see Glaeser (2008) or Moretti (2011)): with free mobility, people should leave declining locations and move to rising ones. These puzzling findings are explained in this paper by the fact that highly indebted counties were attracting more people than other counties before 2008 and stopped doing so as a consequence of the crisis.

In a paper which is closely related to this one, Cadena and Kovak (2013) show that locations more heavily affected by the crisis (using either the construction sector or Mian and Sufi (2013)'s insights as I do) saw declines in Mexican workers but low internal migration responses amongst low-skilled native workers. They do not take into account, however, that the population trends of native low-skilled workers and Mexicans can be different. This is important. When I account for this, for example by directly examining migration rates, I find that natives and immigrants responded similarly to local economic shocks.

More broadly, this paper calls into question the papers that interpret high moving costs as a limiting force for internal migration to mitigate economic shocks (Beaudry et al., 2014), Kennan and Walker, 2011). While there are certainly migration costs, bilateral flows across locations are always positive. Not moving to a location that has been hit by a negative shock is not costly and this is the main mechanism through which internal migration responds to negative shocks. As a result, internal migration is shown to be an important force through which differences across local labor markets are arbitraged away.

Finally, this paper is related to the literature of spatial economics. Unlike most papers in this literature, I investigate short-term responses. It is well documented that places where amenities or local labor market conditions improve attract more people (see Glaeser (2008) or more recently Diamond (2013) ) while locations with deteriorating local conditions suffer from a shrinking population (see Hornbeck (2012), Hornbeck and Naidu (2012) or Autor et al. (Forthcoming)). It has also been documented that people respond to expectations of future positive prospects (Kennan and Walker, 2011). In line with Glaeser and Gyourko (2005) or Notowidigdo (2013), I show that internal local out-migration rates do not respond swiftly to local economic shocks. However, I also 
emphasize the importance of the response of in-migration rates into these places.

\section{Model}

In this section, I introduce the model that guides the empirical section and the evaluation of the longer-run effects of the Great Recession across metropolitan areas. Two features of the model stand out. First, local labor demands in the various locations are downward sloping. This simply means that if more workers move to a particular location wages decrease on impact. Second, workers are constantly deciding where to live in the following period. This creates a constant flow of workers across locations that reacts to unexpected local shocks in particular places. In principle, how these flows of workers react to local shocks could take various forms: increased out-flows or decreased in-flows (or a combination of both). This is an empirical question that is explicitly tackled in the empirical section. The model makes these two possibilities explicit.

The model has $M$ regions - which for most of the empirical part represent metropolitan areas. There is a single final consumption good that is freely traded across regions, at no cost. There is a fixed factor of production, called land, which makes the local labor demand downward sloping. Workers live for infinitely many periods, but they are myopic in that they only care about the next period's location 5 At each point in time they reside in a particular location $m$. Unexpected permanent shocks that affect the local labor market conditions in each location can occur. Workers can then decide whether to stay or move somewhere else in the following period. Workers are small relative to the labor market so they do not take into account the effect that they have on the labor market when relocating.

\section{$2.1 \quad$ Timing}

The timing of the model is the following. At the beginning of each period an unexpected permanent shock can happen in a location. Next, given the current distribution of workers across locations, firms maximize profits and wages are determined. Lastly, given the wages in the economy, workers decide where to live in the following period.

\subsection{Production Function}

The production function in all regions is the same. Each region has a perfectly competitive representative firm producing according to:

$$
Q_{m}=B_{m}\left[\theta_{m} K_{m}^{\rho}+\left(1-\theta_{m}\right) N_{m}^{\rho}\right]^{1 / \rho}
$$

\footnotetext{
${ }^{5}$ See Kennan and Walker (2011) and Monras (2014) for a larger discussion on this point. In Monras (2014) I show that the model can be extended to incorporate more future periods in the migration decision and that the results obtained in that model are similar to what I present here.
} 
where $N_{m}$ is labor or population and $K_{m}$ is land. $\theta_{m}$ represents the different weights or factor specific productivities of the two factors in the production function, while $\rho$ governs the elasticity of substitution between these factors. $B_{m}$ is Total Factor Productivity (TFP) of each location.

\subsection{Labor market}

For simplicity, I assume that the labor market is perfectly competitive and workers inelastically supply all their labor 6 Thus the labor market is determined by firms' behavior:

$$
w_{m}=p_{m}\left(1-\theta_{m}\right) B_{m}^{\frac{\sigma-1}{\sigma}} Q_{m}^{\frac{1}{\sigma}} N_{m}^{\frac{-1}{\sigma}}
$$

where $\sigma=1 /(1-\rho)$ is the elasticity of substitution between labor and land. This defines the labor demand curve. We can normalize $p_{m}=1$. Free trade will guarantee that prices are the same across regions.

A similar equation applies for land and its price $r_{m}$.

\subsection{Location Choice}

The indirect utility of the workers is given by the local wage $w_{m^{\prime}}$, the amenities $A_{m^{\prime}}$ and the idiosyncratic draw they get for location $m^{\prime}$, given that they live in $m$ :

$$
v_{m^{\prime}}^{i}=\ln V_{m^{\prime}}+\epsilon_{m, m^{\prime}}^{i}=\ln A_{m^{\prime}}+\ln w_{m^{\prime}}+\epsilon_{m, m^{\prime}}^{i}
$$

The intuition is straightforward. If an individual $i$ moves to $m^{\prime}$, she will receive wage $w_{m^{\prime}}$ and will enjoy amenity levels $A_{m^{\prime}} \square^{7}$

Note that the indirect utility has a common component to all workers $\ln V_{m^{\prime}}$ that depends on variables at destination and an idiosyncratic component $\epsilon_{m, m^{\prime}}^{i}$ specific to each worker and her current residence.

Thus, workers maximize:

$$
\max _{m^{\prime} \in M}\left\{\ln V_{m^{\prime}}+\epsilon_{m, m^{\prime}}^{i}\right\}
$$

The general solution to this maximization problem gives the probability that an individual $i$ residing in a location $m$ moves to $m^{\prime}$, given current wages and valuations of amenities $\mathbf{A}$, w in

\footnotetext{
${ }^{6}$ It is easy to introduce search and matching frictions, which I do in the appendix.

${ }^{7}$ It is easy to extend this equation to take unemployment rates at destination into account. I do this in the appendix.
} 
every location 8

$$
p_{m, m^{\prime}}^{i}=p_{m, m^{\prime}}(\mathbf{A}, \mathbf{w})
$$

This shapes the flows of workers across locations. By the law of large numbers we can then use equation (4) to obtain the flow of people between $m$ and $m^{\prime}$ :

$$
P_{m, m^{\prime}}=p_{m, m^{\prime}}^{i} * N_{m} \text { for } s \neq s^{\prime}
$$

where $N_{m}$ is the population residing in $m$. Note that this defines a matrix that represents the flows of people between any two locations in the economy.

It is worth emphasizing that this determines the flows of workers, not the final distribution in each location. This is new in the literature of internal migration. It means that the model presented here is dynamic and not static ?

\subsection{Dynamics}

By definition, the number of individuals in $m$ at time $t$ is the number of individuals who were living in that location - possibly times the natural growth rate $n_{m}$ which I assume to be 0 - plus those who arrive minus those who leave:

$$
N_{m}^{\prime}=N_{m}+I_{m}-O_{m}
$$

Thus, internal relocation can take place through either in-migration or through out-migration. We can use the definition of the flow of people across locations to define the in- and out-migration in each location:

$$
\begin{aligned}
I_{m} & =\sum_{j \neq m} P_{j, m} \\
O_{m} & =\sum_{j \neq m} P_{m, j} \\
N_{m}^{\prime} & =\sum_{j} P_{j, s}
\end{aligned}
$$

This notation is useful for the derivation of some of the results.

\footnotetext{
${ }^{8}$ I use bold letters to denote the vector of all the locations in the economy. Note that in general, flows of workers between two locations depend on the entire vector of amenities and wages in all the locations. Later I make simplifying assumptions to obtain tractable functional forms.

${ }^{9}$ See the discussion in section 2.8
} 


\subsection{Equilibrium}

The definition of the equilibrium has two parts. I start by defining the equilibrium in the short run. It satisfies two conditions. First, firms take as given the productivity $B_{m}$, the productivity of each factor $\theta_{m}$ and factor prices in each location to maximize profits. Second, labor markets clear in each location. This equates the supply and the demand for labor and determines the wage in every local labor market. More formally:

Definition I. A short-run equilibrium is defined by the following decisions:

- Given $\left\{\theta_{m}, B_{m}, K_{m}, \sigma, w_{m}, r_{m}\right\}_{m \in M}$ firms maximize profits.

- Labor and land markets clear in each $m \in M$ so that $\left\{w_{m}, r_{m}\right\}$ is determined.

Note that in the short run, the two factors of production are fixed. Thus, changes in technologies or factor quantities directly affect prices. At the end of the period relocation takes place which determines the distribution of workers across space in the following period. We can define the long-run equilibrium by adding an extra condition to the short-run definition. In words, I say that the economy is in long-run equilibrium when bilateral flows of people are equalized across regions. More specifically,

Definition II. Given $\left\{\theta_{m}, B_{m}, K_{m}, \sigma, A_{m}\right\}_{m \in M}$, a long-run equilibrium is defined as a short-run equilibrium with equalized bilateral flows of population across locations. This is:

$$
P_{m, m^{\prime}}=P_{m^{\prime}, m}, \forall m, m^{\prime} \in M
$$

where the flows are determined by the location maximization problem introduced before.

\subsection{Properties of the model}

\subsubsection{Mobility Properties under a nested logit $\epsilon$}

To guide the empirical section I assume that the distribution of the idiosyncratic taste shocks is a nested logit. At the individual level, this means that the home location will be more likely to have a higher draw than any other destination. At the aggregate level, it will look like a representative worker that is deciding as follows: the first part of the decision is whether to stay in $m$ or whether to move out from $m$. The second part is where to move, if the decision in part one was to move out (Anderson et al. 1992). This then translates into how the in-migration or the out-migration rate responds to shocks. I analyze this in what follows. Figure 1 shows this nested structure.

[Figure 1 goes here] 
This decision structure results in a closed form solution for the probability of an individual moving from $m$ to $m^{\prime}$. By multiplying by the number of individuals in each location, we can write the bilateral flows as follows:

$$
P_{m, m^{\prime}}=N_{m} \eta_{m} \frac{V_{m^{\prime}}^{1 / \lambda}}{\sum_{j \in M} V_{j}^{1 / \lambda}}
$$

where $N_{m}$ is the population in $m, \eta_{m}$ is the fraction of people in $m$ that (endogenously) consider relocating and $\lambda$ is the inverse of the elasticity of substitution between different nodes in the second nest (when people decide where to move). Lower values of $\lambda$ make people more sensitive to the local economic conditions at destination.

The expected value of relocating for someone living in $m$ is given by:

$$
\ln V_{-m}=\lambda \ln \sum_{j \in M} V_{j}^{1 / \lambda}
$$

where $\gamma$ is the inverse of the elasticity of substitution in the upper nest, i.e. between staying or leaving the origin. I assume that $\lambda<\gamma$, i.e. that the elasticity of substitution within the lower nest is larger than that of the upper one. In this case,

$$
\eta_{m}=\frac{V_{-m}^{1 / \gamma}}{V_{m}^{1 / \gamma}+V_{-m}^{1 / \gamma}}
$$

This simply says that if economic conditions elsewhere $\left(V_{-m}\right)$ are good or economic conditions in $m\left(V_{m}\right)$ are bad, a higher fraction of the population in $m$ will try to look for a new destination.

It is useful to think what happens in the limiting cases when $\frac{1}{\gamma} \rightarrow \frac{1}{\lambda}$ and $\frac{1}{\gamma} \rightarrow 0$. When $\frac{1}{\gamma} \rightarrow \frac{1}{\lambda}$ staying at the origin stops having a special role. In turn this implies that, in equilibrium, more people will be switching location at each point in time. While this is a possibility, it is at odds with the empirical fact that only a small share of the population (around 3 or 3.5 percent) changes local labor market in a given year.

When $\frac{1}{\gamma} \rightarrow 0$ then $\eta_{m} \rightarrow \frac{1}{2}$. This means that half of the population in a given location decides each period whether they want to relocate and the other half stays no matter what happens in the current location. This might be unrealistic, since we would expect that, if things went bad, a higher share of the population would leave the location in a given period. It is, however, an empirical question. It may also be unrealistic because if half of the population decides on the future location (and more or less locations are equal in terms of expected utility) and there are $M$ locations, then, in equilibrium, only a fraction $\frac{1}{2}\left(1+\frac{1}{M}\right)$ stay in the same location in each period. This is certainly above the empirical fact that around 3 to 3.5 percent of the population do stay where they are from one year to the next one. 
A simple assumption can deal with this issue. Assuming that the positive draw in the location of origin is $\eta-1$ times more likely than any other location implies that:

$$
\eta_{m}=\frac{V_{-s}^{1 / \gamma}}{(\eta-1) V_{m}^{1 / \gamma}+V_{-s}^{1 / \gamma}}
$$

In terms of the decision tree described in Figure 1 this extra assumption simply means that in the upper nest there are $\eta$ branches. The first one is to relocate away from the origin, while the other $\eta-1$ are to stay. In this case, when $\frac{1}{\gamma} \rightarrow 0$ we have that $\eta_{m} \rightarrow \frac{1}{\eta}$ so only a fraction $\frac{1}{\eta}$ looks for a new destination, or conversely, a fraction $\frac{\eta-1}{\eta}$ always decides to stay in the location of origin, no matter what the economic conditions in the various places are. The fact that in equilibrium only 3 to 3.5 percent relocate each year would imply that $\frac{1}{\eta}$ is around 0.03 , something I discuss in greater detail in the last section.

In what follows, I analyze how the population adapts to local shocks. It is convenient to first analyze how the various bilateral flows react when there is an unexpected shock in one of the local labor markets. As will be clear from the proofs, the limiting case of an arbitrarily large number of locations simplifies the algebra considerably.

Lemma 1. If $\epsilon_{m, m^{\prime}}^{i}$ are i.i.d. and drawn from a nested logit distribution with shape parameters $\lambda$ and $\gamma$ then, in the environment defined by the model, we have that:

$$
\begin{gathered}
\frac{\partial \ln P_{j, m}}{\partial \ln w_{m}} \rightarrow \frac{1}{\lambda} \\
\frac{\partial \ln P_{m, m}}{\partial \ln w_{m}} \rightarrow \frac{1}{\lambda}-\frac{1}{\gamma}\left(1-\eta_{m}\right) \\
\frac{\partial \ln P_{j, m}}{\partial \ln w_{j}} \rightarrow-\frac{1}{\gamma}\left(1-\eta_{j}\right) \\
\frac{\partial \ln P_{j, m}}{\partial \ln w_{m^{\prime}}} \rightarrow 0
\end{gathered}
$$

when the number of locations is arbitrarily large.

Proof. See Appendix.

Lemma 1 shows that there will be a first order effect of shocks at destination that is governed by $1 / \lambda$. If a potential destination $m$ increases wages then a larger number of in-migrants from all the other locations will be attracted. Similarly, if wages improve in $m$, more workers who were living in $m$ will decide to stay in $m$. Finally, given the structure of the idiosyncratic taste shocks, 
economic shocks to a third location will have a negligible impact on the bilateral flows between two locations.

The following proposition discusses how much all these responses of the bilateral flows translate into population changes.

Proposition 2. If $\epsilon_{m, m^{\prime}}^{i}$ are i.i.d. and drawn from a nested logit distribution with shape parameters $\lambda$ and $\gamma$ then, in the environment defined by the model, we have that:

$$
\frac{\partial \ln N_{m}^{\prime}}{\partial \ln w_{m}} \rightarrow \frac{1}{\lambda}-\frac{1}{\gamma} \frac{P_{m, m}}{\sum_{l} P_{l, m}}\left(1-\eta_{m}\right)
$$

and

$$
\frac{\partial \ln N_{m}^{\prime}}{\partial \ln w_{m^{\prime} \neq m}} \rightarrow-\frac{1}{\gamma}\left(1-\eta_{m^{\prime}}\right)
$$

when the number of locations is arbitrarily large.

Proof. See Appendix.

Intuitively, proposition 2 says that a positive (resp. negative) shock will increase (resp. decrease) the local population substantially and that it will have spillovers to the rest of the local labor markets that did not experience this shock.

Thinking about population levels or changes in population levels in light of the model hides the fact that net in-migration may be a consequence of either changes in in-migration rates or changes in out-migration rates, or both ${ }^{10} \mathrm{I}$ discuss this in the following proposition.

Proposition 3. If $\epsilon_{m, m^{\prime}}^{i}$ are i.i.d. and drawn from a nested logit distribution with shape parameters $\lambda$ and $\gamma$ then, in the environment defined by the model, we have that:

1. $\frac{\partial \ln I_{m}}{\partial \ln w_{m}}=\frac{1}{\lambda}$

2. $\frac{\partial \ln O_{m}}{\partial \ln w_{m}}=-\frac{1}{\gamma}\left(1-\eta_{m}\right)$

Proof. See Appendix

This last proposition can be re-expressed in terms of migration rates, which may be useful for empirical applications 11

\footnotetext{
${ }^{10}$ Note that we can model productivity evolutions to make the model consistent with the city growth models, see Eeckhout (2004).

${ }^{i 1} \mathrm{In}$ - and out-migration rates are usually stationary series that are easier to analyze empirically.
} 
Corollary 4. If $\epsilon_{m, m^{\prime}}^{i}$ are i.i.d. and drawn from a nested logit distribution with shape parameters $\lambda$ and $\gamma$ then, in the environment defined by the model, we have that:

1. $\frac{\partial\left(I_{m} / N_{m}\right)}{\partial \ln w_{m}}=\frac{1}{\lambda} \frac{I_{m}}{N_{m}}$

2. $\frac{\partial\left(O_{m} / N_{m}\right)}{\partial \ln w_{m}}=-\frac{1}{\gamma}\left(1-\eta_{m}\right) \frac{O_{m}}{N_{m}}$

Proof. See Appendix.

Proposition 3 and Corollary 4 show that the responses of the in-migration rate and out-migration rate are governed by two different parameters.

\subsubsection{The propagation of a local shock}

We have seen that if there is a shock affecting the labor market conditions in one location, there will be some adjustment. We have also seen that this adjustment can come disproportionately from changes in the in-migration rates or out-migration rates. Do these local labor shocks spill over to non-affected locations? If the local labor demand is downward sloping, changes in the distribution of people across space will indeed have consequences on wages. Fewer people will move to the shocked location or more will leave. In either case, the labor supply in that location decreases. This reduced in-migration or increased out-migration becomes an increase in the labor supply in the non-affected locations, which tends to equalize wages across locations. For all this to happen, we need downward sloping labor demands in the short run. In this model, this is a consequence of the fixed factor of production 12

Proposition 5. In the short run, local labor demand is downward sloping.

Proof. See Appendix.

If we know the labor demand elasticity, it is straightforward to compute how the shock propagates, since we have established how much a shock changes population levels in the following period and how much this, in turn, affects wages. In the last section I quantify this process.

\footnotetext{
${ }^{12}$ Note that in spatial equilibrium it cannot be that average utility in a city is (always) increasing in population. If that was the case, more people would move in until everyone in the country lived in the same city. It is usually assumed that an important component of (indirect) utility are wages, thus a similar argument can be made with respect to wages.
} 


\subsubsection{Long-run properties of the model}

In this section, I analyze the properties of the model in the long run, i.e. when bilateral flows between regions are equalized. The following two propositions characterize wage levels in the crosssection in equilibrium. They share many of the properties of standard spatial equilibrium models that are usually meant to capture the long-run distribution of people across space, but add some nuances (Rosen, 1974), (Roback, 1982), Glaeser (2008).

The first property that I discuss is whether there are multiple long-run equilibria or not.

Proposition 6. There are multiple long-run equilibria. However, given an initial distribution of people across space, there is a unique equilibrium.

Proof. See Appendix.

It is worth noting that this model is in line with the importance of location fundamentals or path dependence - which would help to explain the initial distribution of people and economic activity across space - and with the random growth theories - if technologies or shocks are random (Davis and Weinstein, 2002). It would not be hard to include in the model increasing returns to scale and transport costs. This is, however, left outside of this paper.

Corollary 7. In the long run, the marginal mover is indifferent between local labor markets, and consequently workers in particular local labor markets are fully insured against local shocks, which are absorbed nationally. This is the case even if out-migration rates hardly respond to local shocks.

It is worth noting that - in absence of congestion costs - in order to sustain the larger size, workers in big cities need to have higher equilibrium indirect utilities, on average. If this was not the case, bilateral flows would not be equalized. More specifically, the average indirect utility of a worker that resides in $m$ is $A_{m} w_{m}$ while in equilibrium condition says that $A_{m} w_{m} /\left(\eta_{m} N_{m}\right)^{\lambda}$ is equalized across locations. This implies that workers in larger cities $N_{m}$ have, on average, either higher wages or higher amenities that they directly value. There is a large amount of literature documenting that larger cities in fact pay higher wages Duranton and Puga (2004), Rosenthal and Strange (2004) or, more recently, Combes et al. (2012 ${ }^{13}$ These are usually justified as positive agglomeration externalities that make workers more productive in larger cities.

\subsection{Model Discussion}

This model shows that it is at least theoretically possible that a decrease in in-migration rates without any change in out-migration rates can dissipate local negative shocks across space. While

\footnotetext{
${ }^{13}$ Traditionally, economists argued that this compensated the bad amenities of living in the big cities. This view has been called into question by recent papers (Albouy, 2013), (Glaeser and Gyourko 2005).
} 
this may seem natural with the model presented, it is not how researchers have previously analyzed internal migration. In general, researchers have used static models where the discrete location choice determines the final distribution of people across locations, not the flows between locations (see recent examples like Moretti (2011), Diamond (2013) or Notowidigdo (2013)). In those models, there is no distinction between net and gross flows of workers. In fact, only net flows can be obtained as the difference in the spatial distribution of people across locations at different points in time.

To the best of my knowledge, only Coen-Pirani (2010) is well aware of the importance of distinguishing between in- and out- migration rates. In fact, while the model he develops is very different from the one in this paper, the empirical facts he reports are completely in line with the model and the empirical findings I show in what follows. Empirically, Coen-Pirani (2010) reports that in the cross-section, in-migration rates have higher variance than out-migration rates. The intuition for this result in the model presented here is simple. If we think that local shocks happen randomly at different locations, we should observe that in-migration rates tend to be more different across locations than out-migration rates, at least in the cases where the latter do not respond strongly to local economic shocks. Coen-Pirani (2010) also emphasizes that net inflow rates have a smaller variance than in-migration rates but higher than out-migration rates. This is simply a possibility that emerges when there is a positive correlation between in- and out-migration rates, which in the context of the current model, is a consequence of the convergence towards the long-run equilibrium. At a theoretical level, the results presented in this paper are more general than in Coen-Pirani (2010). For instance in Coen-Pirani (2010), migration is totally directed towards the location that suffers a positive matching shock, while in the model presented above, the bilateral flows are across any two locations.

Another closely related paper is Kennan and Walker (2011) 14. Contrary to what I argue in this paper, Kennan and Walker (2011) and other papers using their methodology suggest that migration costs need to be very high in order to be able to explain the low equilibrium internal migration. More precisely the variance of the idiosyncratic taste parameters needs to be sufficiently high so that local conditions do not matter very much. In these circumstances, however, it has to be the case that in-migration rates are very unresponsive to local shocks - something that is completely in contradiction with the evidence that I present in what follows. Thus, when using logit discrete choice models there is a tension between the low equilibrium internal migration rates and the high responsiveness of internal migration to local shocks. By using a nested logit structure, I introduce one extra parameter, and thus the sufficient flexibility to allow both low equilibrium internal migration and high responsiveness of internal migration to local shocks. The key mechanism that the nested logit captures is the asymmetry between the response of the out-migration rate and the in-migration rate. I document at length this asymmetry in what follows.

\footnotetext{
${ }^{14}$ And similarly, the literature on labor relocation across sectors (Artuc et al. 2010)
} 


\section{Empirical Evidence: In- and out-migration rates}

\subsection{Data}

For this paper, I employ four main data sources. I use the American Community Survey data from Ruggles et al. (2008) to compute migration rates across US metropolitan areas, and in particular information on the current and past residents' locations to construct in-migration rates, out-migrations and net migration rates during the Great Recession. I also use the ACS data to compute unemployment rates and average wages across metropolitan areas. My second source is the Bureau of Economic Analysis, whose data allow me to obtain a measure of real gross domestic product per capita. The third and fourth data sources are Census and Current Population Survey data, again from Ruggles et al. (2008). I use these for the long-run section.

More concretely, I define the in-migration rate to metropolitan area $m$ at time $t$ as follows:

$$
\text { In-migration } \text { rate }_{m, t}=\frac{I_{m, t}}{L_{m, t}}
$$

where $I_{m, t}$ denotes the number of individuals that live in $m$ at time $t$ and were living somewhere else at time $t-115$

Similarly, I define the out-migration rate from a metropolitan area $m$ as:

$$
\text { Out-migration } \text { rate }_{m, t}=\frac{O_{m, t}}{L_{m, t}}
$$

where, $O_{m, t}$ denotes the number of individuals that live in $m$ at time $t-1$ and were living somewhere else at time $t . L_{m, t}$ is simply the population at $m$ at time $t$.

The net migration rate is simply the in-migration rate minus the out-migration rate.

If we limit the count of individuals to people of a certain level of education we obtain the inmigration, out-migration and net migration rates of individuals of education $e$. In particular, I use a simple distinction between high- and low-skilled workers. High-skilled workers are defined as those who have attended college (SC), graduated from college (CG) or attended graduate school (GS). The low-skilled are high-school drop-outs (HSDO) and high-school graduates (HS) (see Katz and Murphy (1992), Autor and Katz (1999), Acemoglu and Autor (2011) or Card (2009) for papers using similar classifications).

One limitation of the data set is that I only possess information on metropolitan areas of residence from 2005 until 2011. Before that, ACS reports only the state of residence and the state of residence in the previous year. While those could be used to define local labor markets,

\footnotetext{
${ }^{15}$ I use the variable metarea and migmet1 from Ruggles et al. (2008). I do not use the observations where the metropolitan area is not identified. Also, there are some metropolitan areas for which the variable migmet1 was not constructed. I do not use these metropolitan areas. Equivalently I use the analogous variables at the state or regional level in the longer-run section.
} 
metropolitan areas are a much better approximation of a local labor market ${ }^{16}$ An alternative would have been to use CPS data, in which both state and metropolitan areas are reported. The use of CPS data, however, is limited by its small sample size. Furthermore, concerns have been raised about how the US Census Bureau deals with missing data, which further limit the number of observations available ${ }^{17}$ The sample size is particularly important when studying yearly migration rates since these are usually below 4 percent. By using ACS data I can use more than 250 metropolitan areas, whereas it would be hard to work with more than 50 metropolitan areas using CPS - which explains why I use regions when using CPS data. For a detailed discussion of the data sources available to study internal migration, see Molloy et al. (2011). They argue that recent internal migration is best estimated using ACS data.

When needed, I have merged these data sets by combining the metropolitan area definitions from the BEA and ACS. The place-names usually coincide perfectly. Sometimes the naming differs slightly but it is always clear on inspection when two different names are referring to the same area. Very occasionally, the aggregation is slightly different across data sets. In those cases I needed to use the more aggregate definition of the two data sets. In total, I obtained 250 metropolitan areas of various sizes and characteristics.

\subsection{Summary Statistics}

Although life-long migration rates are relatively high in the US, year-on-year migration rates are more modest (Molloy et al. (2011)). For a typical metropolitan area, around 3.5 percent of its residents lived in a different location the previous year. In fact, migration rates have declined in the last 20 years or so, as documented in Molloy et al. (2011). This decline in migration rates continued in the 2000s, as can be seen in Table 1 when we compare migration rates before and after 2008.

[Table 1 goes here]

There is, however, some heterogeneity in how many people in-migrate or out-migrate from various metropolitan areas. There are some extreme examples, usually in college towns like Bloomington, Indiana and Bryan-College Station, Texas, which have in-migration rates consistently above 15 percent. The bulk of metropolitan areas, however, are not far from the average 3.5 percent. It is usually the case that high in-migration metropolitan areas are also high out-migration metropolitan

\footnotetext{
16 Autor and Dorn (2009) define local labor markets by Commuting Zones in order to include the entire territory of the US; this is one limitation of using metropolitan areas. In this case, I have limited my analysis to the migration rates of the metropolitan areas.

${ }^{17}$ Molloy et al. (2011) reports lower migration rates in CPS than in ACS, something that is explained in Kaplan and Schulhofer-Wohl (2012) as an undocumented error in the Census Bureau's imputation procedure for dealing with missing data in the Current Population Survey.
} 
areas, again, for example, many of the college towns in the US, as is also documented in Coen-Pirani (2010). In the context of the model presented before, this is simply what you would expect if the economy is not far from the long-run spatial equilibrium.

Unsurprisingly, net migration rates are not always close to 0 . Some metropolitan areas are attracting more people than the population they are losing to other metropolitan areas, contributing to their population growth. Figure 2 shows the distribution of net migration rates across metropolitan areas between 2005 and 2010. We see that around half of the metropolitan areas have positive net migration rates, while the other half have negative net migration rates. It is also the case that in every year there are some people leaving and some people moving into every metropolitan area 18 As can be seen, gross migration flows are larger than net migration flows 19

[Figure 2 goes here]

In terms of per capita GDP, we observe in Table 1 that real GDP per capita remained at around $\$ 44,350$ per capita, both for the entire decade of $2000-2010$ and for the post-2008 years. This is mainly explained by the crisis. In 2008 and 2009, GDP per capita decreased on average in most metropolitan areas. It increased in all other years. Figure 3 shows the per capita GDP growth rates across metropolitan areas in 2008 and 2009 and all the other years. We can see that in most metropolitan areas GDP per capita declined in 2008 and 2009 whereas it grew in the other years.

[Figure 3 goes here]

GDP per capita is not the only measure of local level economic activity that may be relevant for mobility. Unemployment rates and local wages are also very important. During the 20082009 period, the share and the magnitude of wage reductions increased. The same is true for unemployment rates 20

[Figure 4 goes here]

All three variables - per capita GDP, wages and unemployment rates - move very similarly. In fact if we look at the elasticities between GPD per capita, wages and unemployment rates

\footnotetext{
${ }^{18}$ The zero out-migration rates in Table 1 are due to sample size, and are probably not true zeros.

${ }^{19}$ This is true both across locations and also industries Saks and Wozniak (2011), Artuc et al. (2010). It is also the case that the average of the absolute value of net-migration rates is significantly larger than either in- or out-migration rates.

${ }^{20}$ Not shown in the paper but available upon request.
} 
(controlling for metropolitan area fixed effects and time dummies), we see that the most responsive was the unemployment rate, followed by wages. Table 2 shows these results. In particular, a 1 percent change in wages is associated with a .26 percentage change in per capita GDP. Similarly, an increase in unemployment rates of 1 percentage point is associated with a decrease in per capita GDP of a bit more than 1.3 percent. These relationships can also be seen when I compute, in the next section, the elasticity of in- and out-migration with respect to all these variables.

[Table 2 goes here]

It is worth emphasizing that while wages may be nominally downward rigid (Daly et al., 2012), this does not imply that they are downward rigid in real terms across all US metropolitan areas. The average wage in metropolitan areas most affected by the crisis did indeed decrease, and moved in similar ways to how unemployment and GDP per capita did.

\subsection{The short-run response of the in- and out- migration rates}

\subsubsection{Empirical Strategy}

One of the main objectives of this paper is to estimate the (short-term) migration response to local economic shocks. This can be estimated using the following specification:

$$
\text { Migration } \text { rate }_{m, t}=\beta X_{m, t}+\delta_{m}+\delta_{t}+\varepsilon_{m, t}^{e}
$$

where Migration rate r,t $_{t}$ is either the number of people that move into metropolitan area $m$ (divided by the population in that area), the number of people that move out of metropolitan area $m$ or the net in-migration to metropolitan $m . \delta_{m}$ are metropolitan area (MSA) fixed effects, while $\delta_{t}$ are year fixed effects. I use the years 2005-2010, both included. $X_{m, t}$ is a measure of local economic activity. I use the three aforementioned measures: (log) GPD per capita, average (log) wage and unemployment rate.

\subsubsection{First Stage: Local economic variables and the crisis}

As said in the introduction, I use two alternative strategies to estimate this elasticity. Both rely on the unexpectedness of the current crisis. First, I use the importance of the construction sector and second, the level of indebtedness of the households. This latter measure is directly taken from Mian and Sufi (2013) and is defined as the debt to income ratio of households in a number of US counties. To obtain a measure of indebtedness at the metropolitan area I simply take the weighted 
(by population) average of the different counties' debt to income ratio whenever the metropolitan area has more than one county. In particular, I run the following regression:

$$
X_{m, t}=\beta * \operatorname{shock}_{t} * Z_{m, T}+\delta_{m}+\delta_{t}+\eta_{m, t}
$$

where $X_{m, t}$ is either (log) per capita GDP, unemployment rate or average (log) wage in metropolitan area $m$ at time $t$, shock $_{t}$ is a dummy variable that takes value 1 after 2008 , and where $Z_{m, T}$ is either the number of workers in construction divided by the total number of workers in metropolitan area $m$ in 2000, the debt to income ratio in 2006, or the interaction of the debt to income ratio in 2006 with the share of workers in non-tradable sectors in 2000, which is a measure of how important the drop in aggregate demand was in the metropolitan area 21 . I call these three alternative strategies, IV1, IV2 and IV3. $\delta_{m}$ are metropolitan area fixed effects, while $\delta_{t}$ are year fixed effects.

Table 3 shows the results of running these regressions. There are at least two remarkable findings. First, all three measures that I use to see what the most affected metropolitan areas were when the crisis hit in 2008 are well correlated with per capita GDP and unemployment rates. Wages, in contrast, seem not to react so much to construction.

Second, the measures related to the indebtedness of the households are much more closely correlated to decreases in GDP, increases in unemployment and decreases in wages. If the aggregate demand channel is as important as Mian and Sufi (2013) argue, this is exactly what we would expect to find.

[Table 3 goes here]

We can also use the same strategies to investigate whether different skill groups are affected equally by the crisis across metropolitan areas. In Table 4 I compute the average (log) wage and the unemployment rates for the low- and high-skilled separately ${ }^{22}$ It shows that the shock affected the unemployment rates of low-skilled workers relatively more than those of high-skilled workers, while it affected wages for high-skilled workers relatively more than it did for low-skilled workers. These results thus suggest that the labor market might be more rigid for low-skilled workers than for high-skilled ones so that adjustments take place in quantities rather than in prices for the former group.

[Table 4 goes here]

\footnotetext{
${ }^{21}$ I follow Mian and Sufi $(2013)$ to define non tradable sectors.

${ }^{22}$ Low-skilled are defined as having finished high school or less. High-skilled are the rest of the population.
} 


\subsubsection{Second Stage: Internal migration rates and the crisis}

If we abstracted from the model presented before, perhaps the most natural measure of local economic activity would be the GDP per capita in different metropolitan areas. Following the overall economy, most metropolitan areas saw decreases in per capita GDP in 2008, as previously documented. Metropolitan areas more dependent on the construction sector and metropolitan areas whose households were more indebted suffered the crisis disproportionately. Previous literature reports that, surprisingly, it seems that more people seemed to move to these metropolitan areas (Mian and Sufi, 2013).

When thinking about population changes it may be worth taking a wider perspective. Many cities grow over long periods. A crisis in a given city might affect its trend without necessarily implying that the city will necessarily lose population.

First, as can be seen in the Table 5 locations heavily dependent on the construction sector and which were (to some extent, though much less) more leveraged were in fact attracting more people than the average metropolitan area. This may be because the construction sector or the local consumption boom attracted many people looking for jobs or simply because, for other unrelated reasons, these were metropolitan areas with higher in-migration rates ${ }^{23}$ What the crisis did was to decrease the rate at which these cities were attracting population. It could well be the case, however, that these cities still attracted more people than other cities, despite the fact that they attracted less people than they used to.

[Table 5 goes here]

A direct way to look at migration responses is to look at migration rates. This has the advantage that we are looking at the migration responses of exactly one cohort in each period, since I use the current residence and the residence in the previous year of the same individual. In this paper, I use the term cohort to refer to all the individuals that I observe in a given year and a given data set.

In Table 6 I show the relation between net in-migration rates and the local labor market economic variables. The results are clear. Net in-migration rates decrease when per capita GDP decreases. A 1 percent decrease in GDP per capita leads to a $.08-.17$ percentage points decrease in the net in-migration rate, as can be seen in Table 6. Similarly a $1 \mathrm{pp}$ increase in the unemployment rate leads to a $.14-.2 \mathrm{pp}$ decrease in net in-migration while a 1 percent decrease in the average wage leads to a $.2-.3 \mathrm{pp}$ decrease.

[Table 6 goes here]

\footnotetext{
${ }^{23}$ Note that in all other dimensions metropolitan areas do not differ significantly.
} 
These responses of net migration rates are entirely due to the response of the in-migration rates, as shown in Table 7 A metropolitan area with a typical in-migration rate of around 3.5 percent would see the in-migration rate drop to around 3.3-3.4 percent as a result of a 1 percent decrease in per capita GDP. In more concrete numbers, this represents .14 percent of the population of any given city. Thus, around 9,000 less people would move into New York City if GDP per capita in New York were to drop by 1 percent. We also see in Table 7 that the adjustment to the crisis takes place through reductions in in-migration rates, rather than increases in out-migration rates.

[Table 7 goes here]

How general is this result? Why does this result seem to contradict some other papers in the literature? I investigate these questions in the following two sections.

\subsubsection{Robustness: High- and low-skilled workers}

Wozniak 2010) emphasizes that high-skilled workers are 5-15 percent more likely to take advantage of good labor market opportunities ${ }^{24}$ Her analysis, however, does not explain how sensitive the decision is of whether to move to particular places when they have been hit by a negative shock.

An ideal experiment to answer whether in-migration rates respond differently to changes in local labor market conditions would be to have a shock that only affects one type of workers. In this paper, the shock affected both high and low-skilled workers. Still, one can compare what happens to changes in wages or unemployment rates of specific groups and changes in internal migration of these groups. In this section I concentrate on in-migration rates, since all the action comes from this variable. The results are shown in Tables 8 and 9

\section{[Table 8 goes here]}

Table 8 shows that the internal migration response of low-skilled workers is very similar to that of the average population shown in Table 7. For example, the estimated elasticity of in-migration rates to per capita GDP is between 9 and 16 percent for the average population while it is from 10 to 17 percent for the low-skilled. Table 8 also shows that this elasticity does not change if we restrict the computation of in-migration rates to native workers. This seems to be in contradiction to the findings in Cadena and Kovak (2013), which I discuss below.

Table 9 shows that the estimates do not change significantly if we restrict attention to highskilled workers. Again the elasticities are similar to the ones computed in Table 7.

\footnotetext{
${ }^{24}$ Literature reviews about internal migration rates include Greenwood (1997).
} 
[Table 9 goes here]

\subsubsection{Robustness: Explaining some results in the literature}

This section explains why both the evidence reported in Mian and Sufi (2013) and in Cadena and Kovak (2013) is not in contradiction with what I report here. It also challenges some of their conclusions.

Explaining Mian and Sufi (2013)

Mian and Sufi (2013) argue that people did not respond by relocating geographically during the Great Recession. To look at this, they regress the population growth rate between 2007 and 2009 on a measure of the debt to income ratio at the county level. They find that population growth and debt to income ratios are not correlated. This evidence leads to their conclusion.

To investigate this, I first show that their findings do not change when, instead of counties, we use metropolitan areas as the unit of analysis. This can easily be seen in Figure 5 . We observe how the fitted values of the regression $\Delta \ln \operatorname{pop}_{c}=\alpha+\beta$ Economic Impact ${ }_{c}+\varepsilon_{c}$ define a straight line between 2006 and 2010. This is true independent of the different measures of economic impact discussed before. Figure 5 also shows that the same regression between 2000 and 2006 gives a steep positive (and statistically significant) slope. In other words, before the crisis, metropolitan areas that were hit harder during the Great Recession were growing more than the others and there was a clear slow down in their population growth rates. This is clearly suggestive that internal migration did respond during the Great Recession.

[Figure 5 goes here]

\section{Explaining Cadena and Kovak (2013)}

To investigate how people respond to local shocks Cadena and Kovak (2013) regress the percentage change in native population between 2006 and 2010 on a measure of how hard the crisis hit across locations. They then repeat the exercise for the percentage change in Mexican population on the same measure of local economic shocks. They obtain a negative correlation in the second regression and a zero (or even slightly positive) coefficient in the first one. This would suggest that the native population is not responsive to negative shocks - as concluded in Mian and Sufi (2013) -, while immigrants, and in particular Mexicans, do respond to negative shocks. Unlike Mian and Sufi (2013), Cadena and Kovak (2013) concentrate on low-skilled workers. 
This strategy misses the fact that population trends might be very different between natives and Mexicans, something that needs to be controlled for. An easy way to look at it is to repeat the same regression Cadena and Kovak (2013) use, but with the population change between 2000 and 2006. The change in trend between 2000-2006 and 2006-2010 is evident both for the Mexicans and for natives. This can be seen in Figure 6, which plots the fitted values of the regressions between 2000 and 2006 and between 2006 and 2010:

[Figure 6 goes here]

In particular, Figure 6 shows that if we relate the growth rate of native population and the debt to income ratio computed in Mian and Suf (2013), we observe that between 2000 and 2006 there is a strong positive relationship. This relationship becomes less strong between 2006 and 2010, precisely when the crisis hits in high debt metropolitan areas. If we look at Mexican immigrants alone, we observe that there was initially a slightly negative relationship, that became even more negative between 2006 and 2010. This change in trend is very similar between natives and immigrants. Knowing these different trends is crucial to interpreting whether only low-skilled immigrants respond to local shocks or whether natives also do, despite the fact that the relationship between native population growth rates and debt to income ratio was not negative between 2006 and 2010 25

\subsection{The longer-run}

\subsubsection{Population growth and internal migration}

The results in the previous section show that the short-run response to a negative economic shock is a decrease in in-migration rates and little changes in the out-migration rates. In this section, I investigate how general this result is by decomposing the population growth rates in different locations between the in- and the out-migration rates in a number of standards data sets.

More precisely, I decompose the population growth rate of a particular cohort of workers as follows:

$$
\frac{N_{m, t}-N_{m-1, t}}{N_{m, t-1}}=\frac{I_{m, t}}{N_{m, t-1}}-\frac{O_{m, t}}{N_{m-1, t}}
$$

where $N_{m, t}$ refers to the cohort of workers that at time $t$ are between 18 and 65 years old in each metropolitan area $m$, and $N_{m, t-1}$ refers to the exact same cohort but at their $t-1$ residence (either 5 or 1 years, depending on whether I use Census or CPS data). Equation 20 exactly decomposes the population growth rates in various metropolitan areas of particular cohorts of workers.

\footnotetext{
${ }^{25}$ I obtain similar results for the alternative measures used in this paper of how hard the crisis hit across locations.
} 
Given that equation 20 is an exact decomposition, we can measure how much of the variance in population growth rates is explained by in-migration rates and how much by out-migration rates. In equations, we can run the following two regressions:

$$
\begin{gathered}
\frac{I_{m, t}}{N_{m-1, t}}=\alpha_{1}+\beta_{1} \frac{N_{m, t}-N_{m-1, t}}{N_{m-1, t}}+\left(+\delta_{m}+\delta_{t}\right)+\varepsilon_{m, t} \\
\frac{O_{m, t}}{N_{m-1, t}}=\alpha_{2}-\beta_{2} \frac{N_{m, t}-N_{m-1, t}}{N_{m-1, t}}+\left(+\delta_{m}+\delta_{t}\right)+\epsilon_{m, t}
\end{gathered}
$$

In this situation, it is necessarily the case that $\beta_{1}+\beta_{2}=1$. $\beta_{1}$ is then the share of the variation explained by the variation in in-migration rates while $\beta_{2}$ is the share explained by the variation in out-migration rates.

Table 10 shows the results from using these decompositions. Across a number of specifications and data sets the message is clear. Most variation in population growth rates, generally above 70 percent (and many times even above 90 percent), is explained by variation in in-migration rates rather than variation in out-migration rates.

In panel A, I show these decompositions at the metropolitan level. We observe that cities grow (or decline) mainly because they have disproportionately high (or low) in-migration rates. This is true for each of the decades considered independently, i.e. 1980 to 2000, and it is also true when pooling all the data together as in Table $10{ }^{26}$ My preferred specification is the one shown in columns (5) and (6) where I include metropolitan area fixed effects - which account for systematic differences in the level of in- and out-migration rates across metropolitan areas - and time fixed effects that account for possible shocks to internal migration at the national level in the given year like different moments of the business cycle. This specification suggests that in-migration accounts for more than 70 percent of the variation of population growth rates across metropolitan areas.

The fact that definitions of metropolitan areas vary slightly across decades, motivates the computation of the exact same decomposition but at the state level. The benefit of this is that state borders do not change across decades, so in- and out- migration rates from states can be computed more reliably and more consistently across decades. This is shown in Panel B of the same Table 10 The picture is virtually the same. Again, in my preferred specification, over 90 percent of the variation in population growth rates across states is accounted for by variation in in-migration rates.

Panel C in Table 10 investigates whether these results are sensitive to the frequency of the data used. Although the regressions using the Great Recession suggest than in-migration rates tend to respond more, this result should also be found using CPS data, and in a much larger time series

\footnotetext{
${ }^{26}$ In fact, when considering every decade on a separate regression, the coefficients on in-migration are always above .9. It is also worth taking into account that there are some metropolitan areas for which out-migration rates cannot be computed and some that did not exist in the 1980 Census. I dropped these metropolitan areas, which leaves me with 158 metropolitan areas.
} 
(1981-2012). In this case, I present internal migration at the regional level. This is due to the fact that there are some small states in the US for which the computation of migration rates is less reliable, due to the lack of individual level observations. The results are, again, very similar. In my preferred specification, we observe how more than 70 percent of the variation in population growth rates is accounted for by variation in in-migration rates.

[Table 10 goes here]

\subsubsection{Population size and internal migration}

A natural consequence of the model is that, in equilibrium, internal migration rates in the crosssection are necessarily smaller in bigger cities or regions. If this was not the case, bilateral flows across locations would not be equalized, and thus the economy would not be in spatial equilibrium as was defined in the first section of the paper. This is an easy prediction to test.

In particular, one can run the following regression:

$$
\text { (ln) } \text { Migrants }_{m t}=\alpha+\beta(\ln ) \text { Population }_{m t}+\left(\delta_{t}\right)+\varepsilon_{m t}
$$

To test if in-migration rates tend to be lower in larger locations, we only need check whether $\beta<127$

Table 11 shows the results of running this regression. It shows that both using metropolitan areas or states, it is always the case that internal migration rates and population size are negatively correlated. This is true both if we weight the observations by the size of the location (to account for measurement error) or if we don't and assume that measurement error is non-existent. The magnitudes suggest that if we double the size of a location then its internal migration rate are around 7-20 percent smaller.

[Table 11 goes here]

It is worth noting that this result, while true in the model presented, need not hold in other spatial equilibrium models. In spatial equilibrium, population levels need to be constant. This implies zero net in-migration rates. These zero net in-migration rates could be the result of any combination of in- and out- migration rates.

\footnotetext{
${ }^{27}$ Note that an alternative would be to regress the (ln) of the migration rates on the (ln) population and test whether $\beta<0$. This, obviously, delivers the same results.
} 


\section{Speed of adjustment}

In the previous sections, I have shown that what determines which regions or cities gain or lose population is more related to the in-migration into particular locations than to the out-migration from these locations. I have also shown that the reaction of the in-migration rates to local shocks is a lot larger than that of out-migration rates. This explains how internal migration helps to dissipate local shocks, even during recessions. In this section, I investigate quantitatively how these local shocks propagate through the local labor markets using a calibrated version of the model with the parameters estimated in the empirical section. In particular, I study the effects of internal migration in mitigating the negative consequences in the metropolitan areas that were most affected during the Great Recession in the US. This shows how important in-migration rate responses are in providing insurance against local shocks.

\subsection{Model Calibration}

There are three key parameters in the model that govern how local shocks spread. The first two have been estimated in the empirical section. Those are the reaction of the in-migration rate (governed by $\lambda$ ) and the out-migration rate (governed by $\gamma$ ) to local shocks. In the empirical section, we see that these are around $1 / \lambda=5$ and $1 / \gamma=0{ }^{28}$

The third key parameter is the local labor demand elasticity. I have not estimated this parameter in this paper, so I need to make some assumptions on it. Based on my previous research Monras (2013) a short-run local labor demand elasticity of -1 is a reasonable parameter. It implies that the production function at the local level is Cobb-Douglas. Other elasticities only change the speed at which the local shocks are transmitted. In any case, the long-run local demand elasticity is close to 0, in line with the research on immigration by Altonji and Card (1991), Card (2001) and Card (2009).

The rest of the parameters are calibrated to match the US data. In particular, I obtain $\theta_{m}$ by looking at the share of output that is devoted to labor. I calibrate $B_{m}$ (the total factor productivity of the city) and the contribution of land - in what follows, I refer to the combination of these two as TFP - as the difference between what is produced and the labor contribution 29

The parameters that are a bit more challenging for the calibration are the city-specific amenity levels. For these, I use the long-run equilibrium condition. In simple words, I assume that in 2005 the US economy was in long-run spatial equilibrium. I observe the average wages and the population levels in all the locations in the US and I infer the amenity levels as the values that

\footnotetext{
${ }^{28}$ For $1 / \lambda=5$ we only need to use the coefficient of the regression of in-migration rates on wages, and multiplied by the equilibrium migration rate of between 3 and 3.5 percent. $1 / \lambda=5$ is a lower bound on the responsiveness of in-migration rates.

${ }^{29}$ More specifically I set $\hat{\theta}_{m}=1-\frac{w_{m}}{Q_{m} / N_{m}}$ and $B_{m} K_{m}^{\theta_{m}}=\frac{Q_{m}}{L_{m}} L_{m}^{\hat{\theta}_{m}}$.
} 
make the bilateral flows of workers across locations stable 30 For this I specifically use the equation 11 discussed in the theory section. More specifically, I chose the parameter $\eta$ as the parameter that ensures that New York's average in-migration rate is at its empirical counterpart of a bit over 3 percent 31

\subsection{Internal migration during the Great Recession}

With all these parameters in hand, I can simulate the model. The question is then how to think about the Great Recession in light of the model. A simple way to do it is to assume that the Great Recession is a loss in the TFP of the cities of various magnitudes. This could represent, for example, the functioning of the financial systems in these different localities, or the importance of particular sectors more affected by the crisis. This change in TFP, however, is unobservable. Instead, one can compare the wages in 2005 and those of 2008, assume that population levels are stable through this period, and infer the TFP in 2008 that would justify the observed wages in 2008. This is how I obtain the levels of TFP that cause certain cities to be more affected by the Great Recession in 2008. I can then feed these values into the model and see the predictions of the model with respect to wage and populations levels and compare them with the data.

It is worth emphasizing that the model provides the effect of internal migration on wages and population levels across locations if nothing else was changing in the economy. In this respect, it isolates the contribution of internal migration to the mitigation of the wage decreases in the most affected locations. From a short-run perspective, we can use the estimates we obtained, together with the assumed local labor demand elasticity, to anticipate the role of decreased in-migration at the local level. The fact that a one percent decrease in wages is associated with a .3 percentage point decrease in the in-migration rate means that, if the local demand elasticity is -1 , the potential mitigation effect of reduced in-migration is around $1 / 3$. This can be shown more graphically (and more completely) with the help of the calibrated model.

[Figure 7 goes here]

The top panel of Figure 7 shows the evolution of wages in three selected cities: New York City, San Francisco and Cleveland. I normalize wages to 1 before the Great Recession hits, although wage levels are not necessarily the same across locations. The inferred change in TFP resulting

\footnotetext{
${ }^{30}$ More explicitly, I equate $P_{m, m^{\prime}}$ and $P_{m^{\prime}, m}$ for all $m, m^{\prime} \in M$ and obtain the amenity levels with respect to a base location. The base location is the first metropolitan area in alphabetical terms.

${ }^{31}$ Note that I could use a different assumption of the year when the US is in long-run spatial equilibrium, since 2005 is an arbitrary choice motivated by the fact that it is the earliest date where I can use ACS data. The results do not change substantially if instead we were to assume another year (or average over some period) as the long-run spatial equilibrium.
} 
from the Great Recession is largest in Cleveland, followed by New York and San Francisco (which in fact is doing slightly better than the national average). This can be appreciated in the wage evolution of the various cities. Cleveland sees a sharp decrease at time 0 that is mitigated in the following periods thanks to internal migration. The shock in New York is less negative, while in San Francisco the shock is roughly equal to the national shock. This means that wages in New York drop initially, but not as much as in Cleveland, and they then slowly recover. In San Francisco they drop initially, but since the city is less affected than the others, wages do not recover (since the shock is no worse than the average shock in the whole of US).

The bottom part of Figure 7 shows how the evolution of wages shapes the evolution of population. We see that since Cleveland's wages drop more than the national average, fewer people are attracted towards Cleveland. This decreases its population level and partially mitigates the negative consequences of the crisis. If we take the wage drop in San Francisco as the level at which Cleveland should have been had it suffered the average negative shock during the Great Recession, we see that wages in Cleveland should have dropped by around 4.2 percent. Instead they drop by almost 7 percent. Once internal migration starts to act, we observe how wages in Cleveland recover a little bit, to a loss of around 5.8 percent. This is a recovery of 1.2 percentage points, roughly one third of the difference between the 4.2 percent loss in San Francisco and the initial 7 percent loss in Cleveland. This happens quite fast, since most of the adjustment has already taken place within the first five years - the first year being the one with the largest adjustment.

The mechanism through which this is happening is, in this calibration, exclusively through reduced in-migration. This is shown in Figure 8

[Figure 8 goes here]

In fact, there are a number of properties of the model that become clear in Figure 8 First, we observe that equilibrium in-migration rates are higher in the smaller city (Cleveland) than in the larger ones. The effect of the Great Recession is a sharp decrease in in-migration rates toward Cleveland, a moderate decrease in New York City, and roughly no effect in San Francisco. This simply reflects the change in wages (relative to the national average) that the Great Recession caused in these three cities.

\subsection{Comparing the model and the data}

To test whether the model captures the wage and population dynamics in the data well, we can compare the wage and population levels predicted by the model and the ones observed in the data. To do so, I report the following regressions: 


$$
X_{m t}=\alpha+\beta \hat{X}_{m t}+\delta_{m}+\delta_{t}+\varepsilon_{m t}
$$

where $X$ indicates either wages or population levels, and $\delta$ are time and metropolitan area fixed effects. The hat indicates that the variable is the one predicted by the model.

[Table 12 goes here]

The results are reported in Table 12 We see that the model predictions are negatively correlated with the actual wage evolution and positively correlated with the population evolution. An interpretation of this result is that the Great Recession was not just a one period shock, but a larger shock to particular metropolitan areas. This made wages in the data in the most negatively affected locations decrease, while in the model they recover thanks to the effect of internal migration. This explains the negative correlation. Another way to put it is that the model is isolating the effect of internal migration on wages. At the same time, the evolution of population levels is in the direction of what is predicted by the model, since affected areas, no matter if they are affected in one period or in multiple, lose population.

\section{Conclusion}

Contrary to previous literature, such as Mian and Sufi (2013), Molloy et al. (2011) and Yagan (2014), I show in this paper that internal migration rates responded to the crisis. Rather than observing populations leaving the hard hit locations, I have documented that fewer people migrated into the locations that suffered more from the crisis. This is important because it helps decrease the labor supply in those metropolitan areas and it spreads the local shocks spatially. Furthermore, I show that this is found both when considering native workers alone, or together with immigrants. When distinguishing by skill, low-skilled workers are shown to be more responsive to unemployment rates while high-skilled workers respond more to wage changes.

This paper also shows how differences in in-migration rates may be crucial for the understanding of city growth. Across a number of data sets and time periods, I show how most of the variance in population growth rates across cities is accounted for by variance in in-migration rates. In all, this paper shows that internal mobility helps mitigate negative shocks at the local level. 


\section{References}

Acemoglu, D. and D. Autor, "Skills, Tasks and Technologies: Implications for Employment and Earnings," Handbook of Labor Economics Volume 4, Orley Ashenfelter and David E. Card (eds.), 2011.

Albouy, D., "Are Big Cities Bad Places to Live? Estimating Quality of Life across Metropolitan Areas," mimeo, 2013.

Altonji, J. and D. Card, "The Effects of Immigration on the Labor Market Outcomes of LessSkilled Natives," in John Abowd and Richard Freeman (eds.), Immigration, Trade, and the Labor Market, University of Chicago Press, 1991.

Anderson, S., A. De Palma, and J-F. Thisse, "Discrete Choice Theory of Product Differentiation," MIT Press, 1992.

Artuc, E., S. Chaudury, and J. McLaren, "Trade Shocks and Labor Adjustment: A Structural Empirical Approach," American Economic Review, 2010.

Autor, D. and D. Dorn, "This Job Is 'Getting Old:' Measuring Changes in Job Opportunities Using Occupational Age Structure.," American Economic Review Papers and Proceedings, 2009.

- and L. Katz, "Changes in the Wage Structure and Earnings inequality," Handbook of Labor Economics, 1999.

_, D. Dorn, and D. Hanson, "The China Syndrome: Local Labor Market Effects of Import Competition in the United States," American Economic Review, Forthcoming.

Beaudry, P., D. Green, and B. Sand, "Spatial Equilibrium with Unemployment and Wage Bargaining: Theory and Estimation," mimeo, 2014.

Blanchard, O. and L. Katz, "Regional Evolutions," Brookings Papers on Economic Activity, 1992, pp. 1-75.

Cadena, B. and B. Kovak, "Immigrants Equilibrate Local Labor Markets: Evidence from the Great Recession," mimeo, 2013.

Card, D., "Immigrant Inflows, Native Outflows and the Local Labor Market Impacts of Higher Immigration," Journal of Labor Economics, 2001, 19.

_ , "Immigration and Inequality," American Economic Review Papers and Proceedings, 2009, 99(2), $1-21$. 
Coen-Pirani, D., "Understanding gross worker flows across U.S. states," Journal of Monetary Economics, 2010.

Combes, P-P., G. Duranton, L. Gobillon, D. Puga, and S. Roux, "The productivity advantages of large cities: Distinguishing agglomeration from firm selection," Econometrica, 2012, 80(6), 2543-2594.

Daly, M., B. Hobijn, and B. Lucking, "Why Has Wage Growth Stayed Strong," FRBSF Economic Letter, 2012.

Davis, D. and D. Weinstein, "Bones, Bombs, and Break Points: The Geography of Economic Activity," American Economic Review, 2002, 92(5), Lead Article.

Diamond, R., "The Determinants and Welfare Implications of US Workers' Diverging Location Choices by Skill: 1980-2000," mimeo, 2013.

Duranton, G. and D. Puga, "Micro-Foundations of Urban Agglomeration Economies," Handbook of Regional and Urban Economics, ed. Hendersson and Thisse, 2004.

Eeckhout, J., "Gibrat's Law for (All) Cities," American Economic Review, 2004, 94 (5), 14291451.

Gabaix, X., "Zipf's Law for Cities: An Explanation," Quarterly Journal of Economics, 1999.

Glaeser, E., Cities, Agglomeration and Spatial Equilibrium, Oxford University Press, 2008.

- and J. Gyourko, "Urban Decline and Durable Housing," Journal of Political Economy, 2005, 113(2), 345-375.

Greenwood, M., "Internal Migration in Developed Countries," Handbook of Population and Family Economicsed. Mark R. Rosenzweig and Oded Stark. New York: Elsevier Science., 1997.

Hornbeck, R., "The Enduring Impact of the American Dust Bowl: Short- and Long-run Adjustments to Environmental Catastrophe," American Economic Review, 2012, 102(4), 1477-1507.

- and S. Naidu, "When the Levee Breaks: Black Migration and Economic Development in the American South," NBER WP n. 18296, 2012.

Kaplan, G. and S. Schulhofer-Wohl, "Interstate Migration Has Fallen Less Than You Think: Consequences of Hot Deck Imputation in the Current Population Survey," Demography, 2012.

Katz, L and K. Murphy, "Changes in Relative Wages, 1963-1987: Supply and Demand Factors," Quarterly Journal of Economics, 1992, 107(1), 35-78. 
Kennan, J. and J. Walker, "The Effect of Expected Income on Individual Migration Decisions," Econometrica, 2011, 79(1), 211-251.

Mian, A. and A. Sufi, "What Explains High Unemployment? The Aggregate Demand Channel," mimeo, 2013.

Molloy, R., C. Smith, and A. Wozniak, "Internal Migration in the United States," Journal of Economic Perspectives, 2011, 25(3), 173-196.

Monras, J., "Immigration and Wage Dynamics: Evidence from the Mexican Peso Crisis," Columbia University Discussion Paper Series, 2013.

_ , "Essays in Internal and International Migration," Columbia University, 2014.

Moretti, E., "Local Labor Markets," Handbook of Labor Economics, 2011.

_, "What Workers Lose by Staying Put," Wall Street Journal, 2012.

Notowidigdo, M., "The Incidence of Local Labor Demand Shocks," mimeo, 2013.

Pissarides, C., Equilibrium Unemployment Theory 2000.

Roback, J., "Wages, Rents, and the Quality of Life," Journal of Political Economy, 1982, 90(6), $1257-1278$.

Rosen, S., "Hedonic Prices and Implicit Markets: Product Differentiation in Pure Competition," Journal of Political Economy, 1974, 82, 34-55.

Rosenthal, S.S. and W. Strange, "Evidence on the Nature and Sources of Agllomeration Economies," Handbook of Regional and Urban Economics, ed. Hendersson and Thisse, 2004.

Ruggles, S., M. Sobek, T. Alexander, C.A. Fitch, R. Goeken, PK Hall, M. King, and C. Ronnander, "Integrated Public Use Microdata Series: Version 4.0 [Machine-readable database].," Minneapolis, MN: Minnesota Population Center [producer and distributor], 2008.

Saks, R. and A. Wozniak, "Labor Reallocation over the Business Cycle: New Evidence from Internal Migration," Journal of Labor Economics, 2011, 29(4), 697-739.

Topel, R., "Local Labor Markets," Journal of Political Economy, 1986, 94(3), S111-S143.

Wozniak, A., "Are College Graduates More Responsive to Distant Labor Market Opportunities?," Journal of Human Resources, 2010, 45(4), 944-970.

Yagan, D., "Moving to Opportunity? Migratory Insurance over the Great Recession," Job Market Paper, 2014. 


\section{$6 \quad$ Figures}

Figure 1: Migration decision from an aggregate perspective

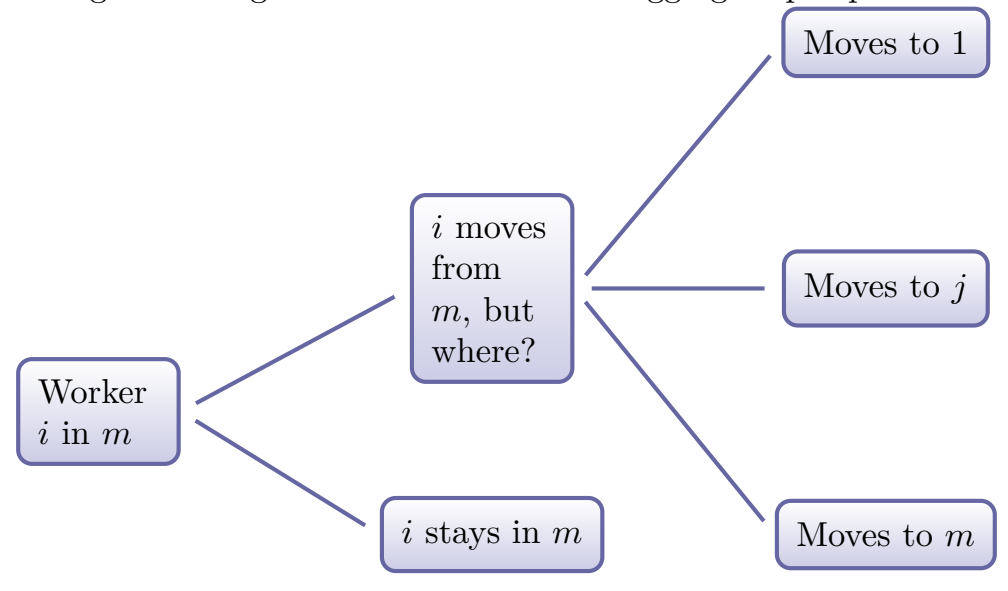


Figure 2: Net migration rates across metropolitan areas

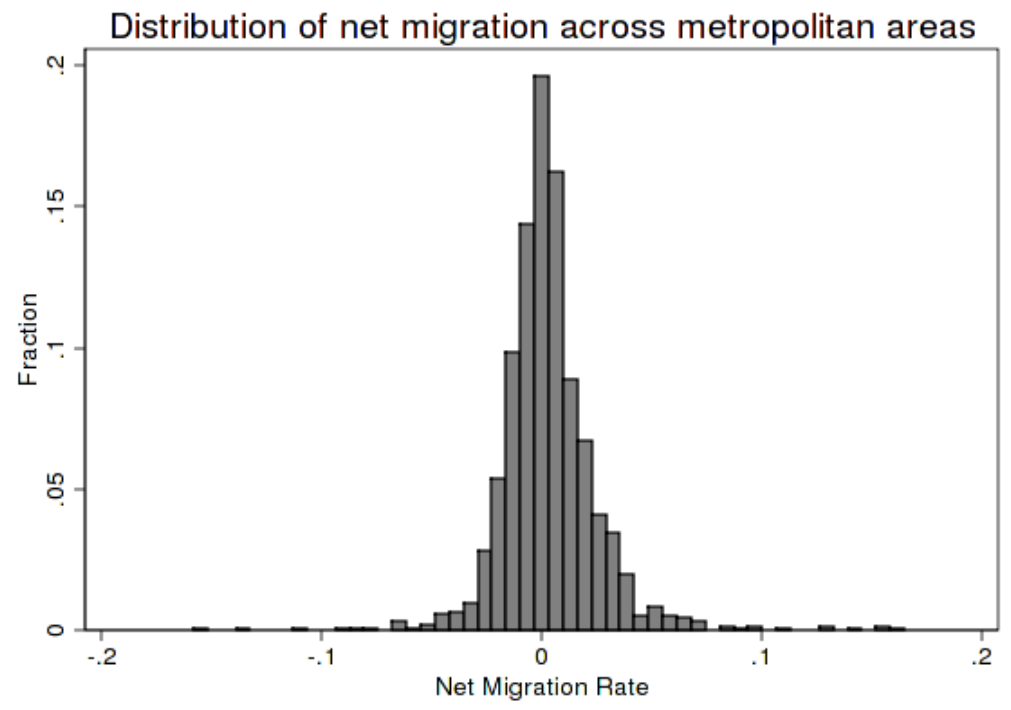

Notes: Net migration is computed from the people that move into and out of each metropolitan area. I have used data from 250 different metropolitan areas between 2006 and 2010. Source: ACS data from Ruggles et al. (2008). 
Figure 3: GDP per capita growth rates across metropolitan areas
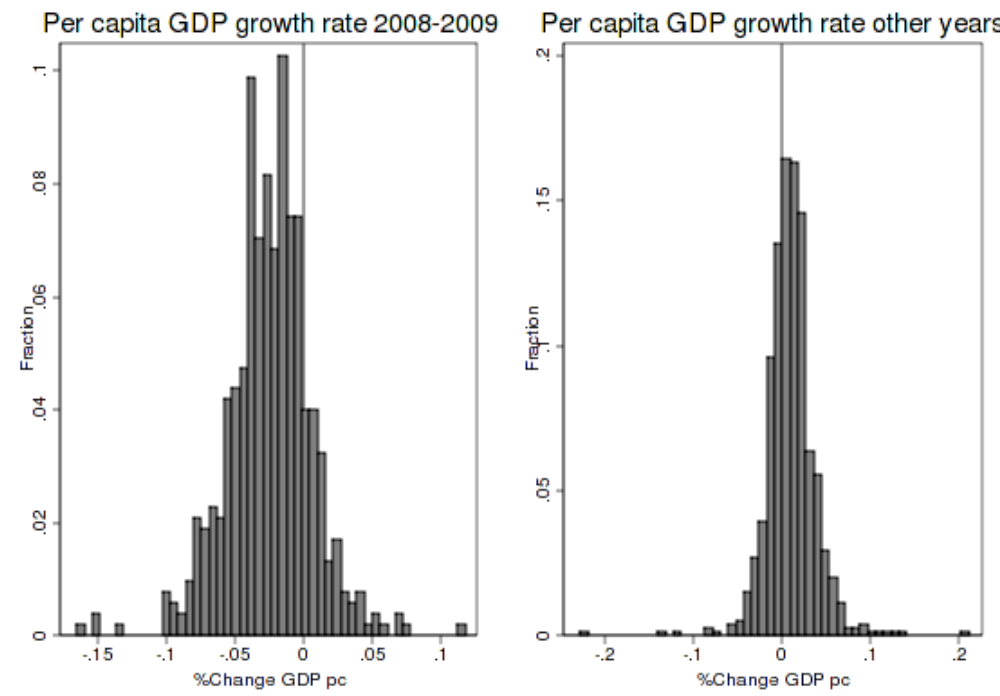

Notes: This figure shows the per capita real GDP growth rates in all 250 metropolitan areas. Vertical lines distinguish positive from negative growth rates. Source: BEA. 
Figure 4: Wage growth rates across metropolitan areas
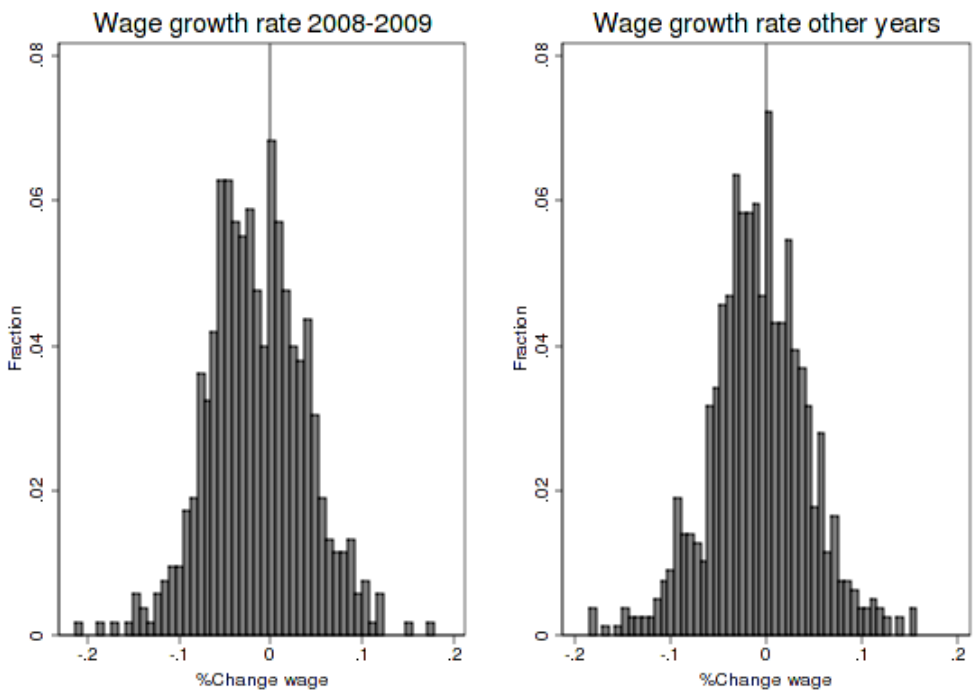

Notes: This figure shows average real wage growth rates in all 250 metropolitan areas. Vertical lines distinguish positive from negative growth rates. Source: Ruggles et al. (2008). 
Figure 5: Pre-trends in population growth rates
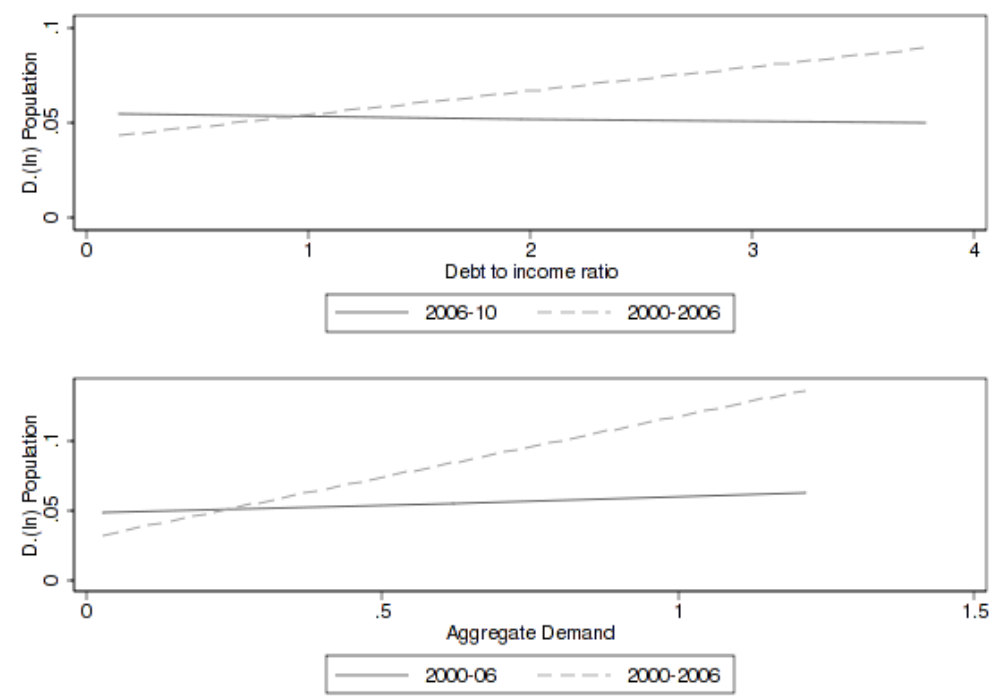

Notes: This graph shows the pre trends in population growth rates relative to a measure of how hard the crisis hit at a local level. 
Figure 6: Differential trends between low-skilled natives and immigrants
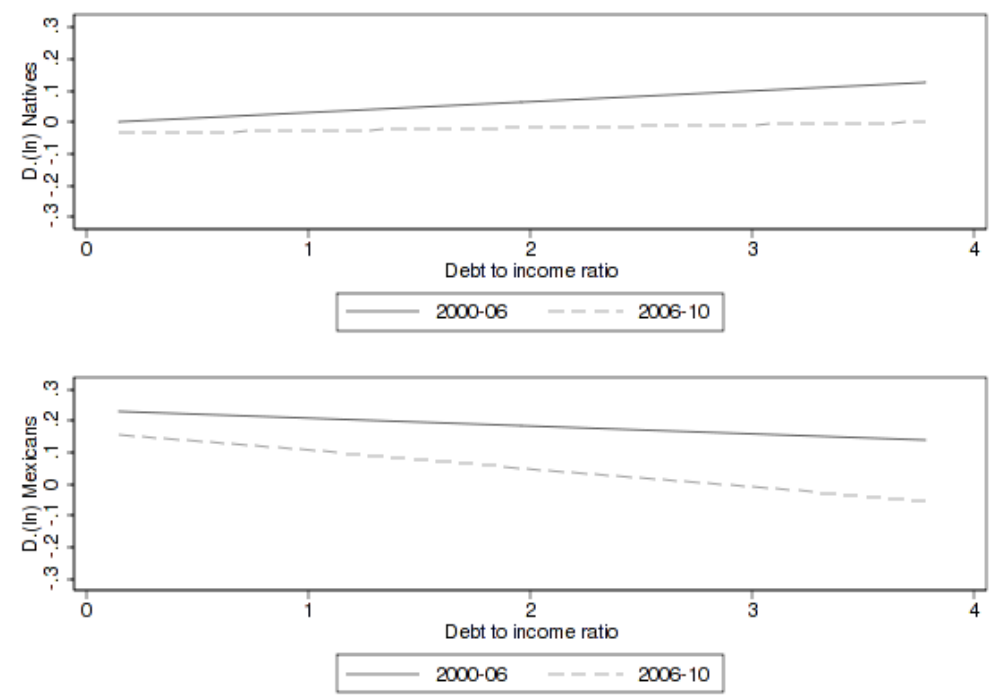

Notes: This graph shows the different trends in native and immigrant low-skilled population relative to a measure of how hard the crisis hit at a local level. 
Figure 7: The evolution of the wages and population in the model, selected metropolitan areas
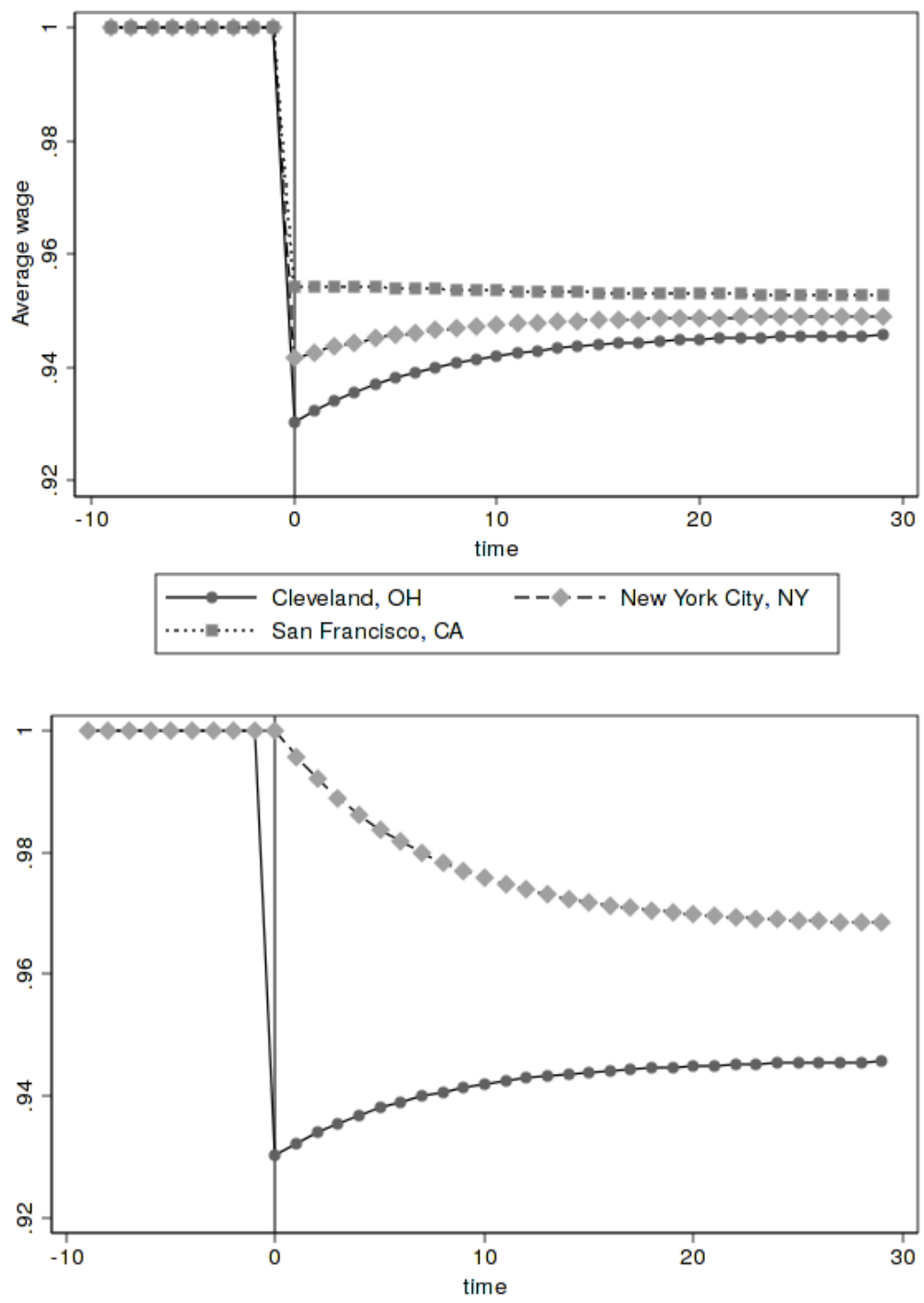

Wage in Cleveland, $\mathrm{OH}$

$--\rightarrow-$ Population in Cleveland, $\mathrm{OH}$

Notes: This graph shows the evolution of wages and population in a number of cities according to the model calibrated to match the implied productivity loss during the Great Recession. See more details in the text. 
Figure 8: The evolution of the in-migration rate in the model, selected metropolitan areas

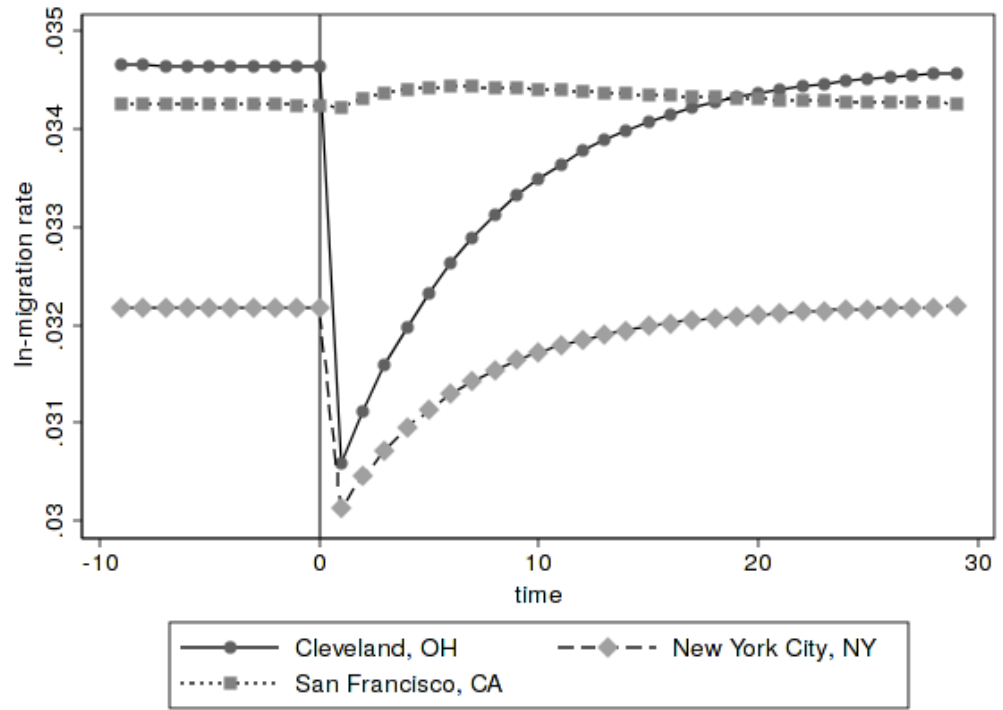

Notes: This graph shows the evolution of the in-migration rate in a number of cities according to the model calibrated to match the implied productivity loss during the Great Recession. See more details in the text. 


\section{Tables}

Table 1: Summary statistics

\begin{tabular}{|c|c|c|c|c|c|}
\hline Variable & Mean & Std. Dev. & Min. & Max. & $\mathbf{N}$ \\
\hline & \multicolumn{5}{|c|}{$2005-2010$} \\
\hline Population & $537,528.103$ & $1,090,815.234$ & 58,743 & $11,317,911$ & 1500 \\
\hline Microdata Obs & 440.121 & 787.33 & 20 & 6483 & 1500 \\
\hline In-migration rate & 0.044 & 0.022 & 0.003 & 0.192 & 1500 \\
\hline In-migration rate, low & 0.042 & 0.029 & 0 & 0.238 & 1500 \\
\hline In-migration rate, high & 0.046 & 0.021 & 0 & 0.169 & 1500 \\
\hline Out-migration rate & 0.043 & 0.019 & 0.004 & 0.179 & 1500 \\
\hline Out-migration rate, low & 0.036 & 0.019 & 0.003 & 0.196 & 1500 \\
\hline Out-migration rate, high & 0.049 & 0.023 & 0.003 & 0.211 & 1500 \\
\hline Net in-migration rate & 0.001 & 0.019 & -0.158 & 0.113 & 1500 \\
\hline (ln) GDP pc & 10.5 & 0.268 & 9.666 & 11.418 & 1500 \\
\hline Wage & 6.063 & 0.133 & 5.697 & 6.589 & 1500 \\
\hline \multirow[t]{2}{*}{ Unemploy. rate } & 0.081 & 0.029 & 0.013 & 0.198 & 1500 \\
\hline & \multicolumn{5}{|c|}{ After 2008} \\
\hline Population & $550,345.599$ & $1,110,886.567$ & 60,720 & $11,317,911$ & 750 \\
\hline Microdata Obs & 435.775 & 787.739 & 20 & 6483 & 750 \\
\hline In-migration rate & 0.043 & 0.023 & 0.003 & 0.192 & 750 \\
\hline In-migration rate, low & 0.043 & 0.03 & 0 & 0.238 & 750 \\
\hline In-migration rate, high & 0.044 & 0.021 & 0 & 0.169 & 750 \\
\hline Out-migration rate & 0.041 & 0.017 & 0.004 & 0.162 & 750 \\
\hline Out-migration rate, low & 0.034 & 0.017 & 0.003 & 0.162 & 750 \\
\hline Out-migration rate, high & 0.047 & 0.021 & 0.003 & 0.161 & 750 \\
\hline Net in-migration rate & 0.003 & 0.018 & -0.109 & 0.113 & 750 \\
\hline (ln) GDP pc & 10.487 & 0.271 & 9.666 & 11.418 & 750 \\
\hline Wage & 6.046 & 0.131 & 5.734 & 6.528 & 750 \\
\hline Unemploy rate & 0.093 & 0.032 & 0.025 & 0.198 & 750 \\
\hline
\end{tabular}

Notes: Those are summary statistics for 250 metropolitan areas between 2005-2010 using ACS data. Statistics are computed for working age population. 
Table 2: The covariance between GDP per capita, wage and unemployment rate

\begin{tabular}{lccc}
\hline & $(1)$ & $(2)$ & $(3)$ \\
VARIABLES & OLS & $\begin{array}{c}\text { GDP pc } \\
\text { OLS }\end{array}$ & $\begin{array}{c}\text { Wage } \\
\text { OLS }\end{array}$ \\
\hline (ln) wage & & & \\
& $0.261^{* * *}$ & & \\
Unemployment rate & $(0.0557)$ & & \\
& & $-1.339^{* * *}$ & $-0.574^{* * *}$ \\
& & $(0.177)$ & $(0.0936)$ \\
Observations & 1,500 & 1,500 & 1,500 \\
R-squared & 0.991 & 0.993 & 0.979 \\
Metropolitan FEs & yes & yes & yes \\
Time FEs & yes & yes & yes \\
\hline
\end{tabular}

Notes: This table shows the elasticities between GDP per capita, wages, and unemployment rates. Each elasticity is computed from an OLS regression. Only one variable and the fixed effects are included as explanatory variables in the OLS regressions. ${ }^{*} \mathrm{p}<.1,{ }^{* *} \mathrm{p}<.05$ and ${ }^{* * *} \mathrm{p}<.001$. 
Table 3: First Stage: Construction sector, Household Debt and Aggregate Demand

\begin{tabular}{|c|c|c|c|c|c|c|c|c|c|}
\hline VARIABLES & $\begin{array}{c}\text { (1) } \\
\text { GDP pc } \\
\text { OLS }\end{array}$ & $\begin{array}{c}(2) \\
\text { GDP pc } \\
\text { OLS }\end{array}$ & $\begin{array}{c}(3) \\
\text { GDP pc } \\
\text { OLS }\end{array}$ & $\begin{array}{c}(4) \\
\text { Wage } \\
\text { OLS }\end{array}$ & $\begin{array}{c}(5) \\
\text { Wage } \\
\text { OLS }\end{array}$ & $\begin{array}{c}(6) \\
\text { Wage } \\
\text { OLS }\end{array}$ & $\begin{array}{c}(7) \\
\text { Unemploy. } \\
\text { rate } \\
\text { OLS } \\
\end{array}$ & $\begin{array}{c}(8) \\
\text { Unemploy. } \\
\text { rate } \\
\text { OLS } \\
\end{array}$ & $\begin{array}{c}(9) \\
\text { Unemploy } \\
\text { rate } \\
\text { OLS }\end{array}$ \\
\hline Share of Construction, IV1 & $\begin{array}{c}-1.631^{* * *} \\
(0.351)\end{array}$ & & & $\begin{array}{l}0.0435 \\
(0.201)\end{array}$ & & & $\begin{array}{c}0.335 * * \\
(0.164)\end{array}$ & & \\
\hline Debt to Income ratio, IV2 & & $\begin{array}{c}-0.0204^{* * *} \\
(0.00690)\end{array}$ & & & $\begin{array}{c}-0.00728^{* * *} \\
(0.00213)\end{array}$ & & & $\begin{array}{c}0.0112 * * * \\
(0.00191)\end{array}$ & \\
\hline Aggregate Demand, IV3 & & & $\begin{array}{c}-0.0974^{* * * *} \\
(0.0223)\end{array}$ & & & $\begin{array}{c}-0.0304^{* * *} \\
(0.00777)\end{array}$ & & & $\begin{array}{r}0.0448^{* * *} \\
(0.00642)\end{array}$ \\
\hline Observations & 1,500 & 1,164 & 1,164 & 1,500 & 1,164 & 1,164 & 1,500 & 1,164 & 1,164 \\
\hline R-squared & 0.992 & 0.991 & 0.992 & 0.978 & 0.980 & 0.980 & 0.860 & 0.890 & 0.895 \\
\hline Metropolitan FEs & yes & yes & yes & yes & yes & yes & yes & yes & yes \\
\hline Time FEs & yes & yes & yes & yes & yes & yes & yes & yes & yes \\
\hline
\end{tabular}

Notes: The dependent variable is (log) GDP per capita, the unemployment rate and average wages in metropolitan areas. The table shows the results of running $7 \times 3$ different regressions. 'Construction shock' is the interaction of the share of construction workers in 2000 with a dummy taking value 1 in the years after the beginning of the Great Recession, i.e. 2008-10. 'HH debt shock' is the interaction of Mian and Sufi 2013, measure of

Household indebtedness with a dummy taking value 1 in the years after the beginning of the Great Recession. 'AD employ shock' is the interaction of Mian and Suf 2013) measure of Household indebtedness with the share of workers in the non tradable sector and a dummy taking value 1 in the years after the beginning of the Great Recession. Regressions are weighted by the number of observations in each metropolitan area. Number of observations: 250 metropolitan areas x 6 years $=1500$ or 194 metropolitan areas x 6 years $=1164$ when Mian and Sufi (2013), measure used. * p<.1, $* * \mathrm{p}<.05$ and $* * * \mathrm{p}<.001$. 
Table 4: First Stage: Construction sector, Household Debt and Aggregate Demand, by skills

Panel A: Wages by skill

\begin{tabular}{|c|c|c|c|c|c|c|}
\hline VARIABLES & $\begin{array}{c}\text { (1) } \\
\text { Wage } \\
\text { LS } \\
\text { OLS }\end{array}$ & $\begin{array}{c}(2) \\
\text { Wage } \\
\text { LS } \\
\text { OLS } \\
\end{array}$ & $\begin{array}{c}(3) \\
\text { Wage } \\
\text { LS } \\
\text { OLS } \\
\end{array}$ & $\begin{array}{c}(4) \\
\text { Wage } \\
\text { HS } \\
\text { OLS }\end{array}$ & $\begin{array}{c}(5) \\
\text { Wage } \\
\text { HS } \\
\text { OLS }\end{array}$ & $\begin{array}{c}(6) \\
\text { Wage } \\
\text { HS } \\
\text { OLS } \\
\end{array}$ \\
\hline Share of Construction, IV1 & $\begin{array}{c}0.198 \\
(0.232)\end{array}$ & & & $\begin{array}{l}-0.165 \\
(0.201)\end{array}$ & & \\
\hline Debt to Income ratio, IV2 & & $\begin{array}{c}-0.00661^{* *} \\
(0.00265)\end{array}$ & & & $\begin{array}{c}-0.0102^{* * *} \\
(0.00223)\end{array}$ & \\
\hline Aggregate Demand, IV3 & & & $\begin{array}{c}-0.0263^{* * *} \\
(0.00870)\end{array}$ & & & $\begin{array}{c}-0.0421^{* * *} \\
(0.00826)\end{array}$ \\
\hline Observations & 1,500 & 1,164 & 1,164 & 1,500 & 1,164 & 1,164 \\
\hline R-squared & 0.901 & 0.909 & 0.909 & 0.975 & 0.977 & 0.978 \\
\hline Metropolitan FEs & yes & yes & yes & yes & yes & yes \\
\hline Time FEs & yes & yes & yes & yes & yes & yes \\
\hline
\end{tabular}

Panel B: Unemployment rates by skill

\begin{tabular}{|c|c|c|c|c|c|c|}
\hline VARIABLES & $\begin{array}{c}(1) \\
\text { Unemploy. } \\
\text { rate } \\
\text { LS } \\
\text { OLS }\end{array}$ & $\begin{array}{c}(2) \\
\text { Unemploy. } \\
\text { rate } \\
\text { LS } \\
\text { OLS }\end{array}$ & $\begin{array}{c}(3) \\
\text { Unemploy. } \\
\text { rate } \\
\text { LS } \\
\text { OLS }\end{array}$ & $\begin{array}{c}(4) \\
\text { Unemploy. } \\
\text { rate } \\
\text { HS } \\
\text { OLS }\end{array}$ & $\begin{array}{c}(5) \\
\text { Unemploy. } \\
\text { rate } \\
\text { HS } \\
\text { OLS }\end{array}$ & $\begin{array}{c}(6) \\
\text { Unemploy. } \\
\text { rate } \\
\text { HS } \\
\text { OLS }\end{array}$ \\
\hline Share of Construction, IV1 & $\begin{array}{c}0.492^{* *} \\
(0.221)\end{array}$ & & & $\begin{array}{c}0.149 \\
(0.115)\end{array}$ & & \\
\hline Debt to Income ratio, IV2 & & $\begin{array}{c}0.0138 * * * \\
(0.00277)\end{array}$ & & & $\begin{array}{c}0.00832^{* * *} * \\
(0.00115)\end{array}$ & \\
\hline Aggregate Demand, IV3 & & & $\begin{array}{c}0.0561^{* * *} \\
(0.00935)\end{array}$ & & & $\begin{array}{c}0.0313^{* * *} \\
(0.00461)\end{array}$ \\
\hline Observations & 1,500 & 1,164 & 1,164 & 1,500 & 1,164 & 1,164 \\
\hline R-squared & 0.841 & 0.869 & 0.874 & 0.823 & 0.863 & 0.864 \\
\hline Metropolitan FEs & yes & yes & yes & yes & yes & yes \\
\hline Time FEs & yes & yes & yes & yes & yes & yes \\
\hline
\end{tabular}

Notes: The dependent variable is (log) GDP per capita, the unemployment rate and average wages in metropolitan areas. The table shows the results of running $7 \times 3$ different regressions. 'Construction shock' is the interaction of the share of construction workers in 2000 with a dummy taking value 1 in the years after the beginning of the Great Recession, i.e. 2008-10. 'HH debt shock' is the interaction of Mian and Sufi (2013) measure of Household indebtedness with a dummy taking value 1 in the years after the beginning of the Great Recession. 'AD employ shock' is the interaction of Mian and Suf (2013) measure of Household indebtedness with the share of workers in the non tradable sector and a dummy taking value 1 in the years after the beginning of the Great Recession. Regressions are weighted by the number of observations in each metropolitan area. Number of observations: 250 metropolitan areas x 6 years $=1500$ or 194 metropolitan areas x 6 years $=1164$ when Mian and Sufi (2013) measure used. ${ }^{*} \mathrm{p}<.1,{ }^{* *} \mathrm{p}<.05$ and ${ }^{* * *} \mathrm{p}<.001$. 
Table 5: Comparing different metropolitan areas

\begin{tabular}{lcc}
\hline & High construction MSAs & Low construction MSAs \\
Population & 523,060 & 731,542 \\
(ln) GDP pc & 10.669 & 10.818 \\
Unemploy. rate & 0.065 & 0.067 \\
In-migration rate & 0.048 & 0.033 \\
Out-migration rate & 0.039 & 0.037 \\
Net in-migration rate & 0.009 & -0.004 \\
Share construction in 2000 & 0.079 & 0.057 \\
Debt to income ratio & 1.793 & 1.789 \\
AD employment & 0.226 & 0.202 \\
\hline & High leveraged MSAs & Low leveraged MSAs \\
Population & 751,824 & 502,778 \\
(ln) GDP pc & 10.739 & 10.755 \\
Unemploy. rate & 0.065 & 0.067 \\
In-migration rate & 0.042 & 0.039 \\
Out-migration rate & 0.040 & 0.036 \\
Net in-migration rate & 0.002 & 0.002 \\
Share construction in 2000 & 0.068 & 0.067 \\
Debt to income ratio & 2.297 & 1.035 \\
AD employment & 0.222 & 0.201 \\
\hline & High AD employ. MSAs & Low AD employ. MSAs \\
Population & 742,330 & 512,271 \\
(ln) GDP pc & 10.739 & 10.755 \\
Unemploy. rate & 0.065 & 0.067 \\
In-migration rate & 0.042 & 0.039 \\
Out-migration rate & 0.040 & 0.037 \\
Net in-migration rate & 0.002 & 0.014 \\
Share construction in 2000 & 0.068 & 0.015 \\
Debt to income ratio & 2.305 & 0.643 \\
AD employment & 0.223 & 0.045 \\
\hline Number of MSAs & 97 & 97 \\
\hline
\end{tabular}

Notes: This table shows the averages of selected variables splitting MSAs by high/low construction, debt to income ratio and $\mathrm{AD}$ employment. $\mathrm{AD}$ employment is the interaction of the share of workers in non-tradable sectors in 2000 with the debt to income ratio. The 194 MSAs - for which I have debt to income ratios- are split in two groups of 97. The year is 2006. Source: ACS data and Mian and Sufi (2013). 
Table 6: The migration response to the crisis: Net In-migration rates, total population

\begin{tabular}{|c|c|c|c|c|c|c|c|}
\hline VARIABLES & $\begin{array}{c}(1) \\
\text { Net-In-migration } \\
\text { rate } \\
\text { IV1 }\end{array}$ & $\begin{array}{c}(2) \\
\text { Net-In-migration } \\
\text { rate } \\
\text { IV2 }\end{array}$ & $\begin{array}{c}(3) \\
\text { Net-In-migration } \\
\text { rate } \\
\text { IV3 }\end{array}$ & $\begin{array}{c}(4) \\
\text { Net-In-migration } \\
\text { rate } \\
\text { IV2 }\end{array}$ & $\begin{array}{c}(5) \\
\text { Net-In-migration } \\
\text { rate } \\
\text { IV3 }\end{array}$ & $\begin{array}{c}(6) \\
\text { Net-In-migration } \\
\text { rate } \\
\text { IV2 } \\
\end{array}$ & $\begin{array}{c}(7) \\
\text { Net-In-migration } \\
\text { rate } \\
\text { IV3 } \\
\end{array}$ \\
\hline (ln) per capita GDP & $\begin{array}{c}0.170 * * * \\
(0.0294)\end{array}$ & $\begin{array}{l}0.0769 * \\
(0.0459)\end{array}$ & $\begin{array}{c}0.0915^{* *} \\
(0.0364)\end{array}$ & & & & \\
\hline Unemployment rate & & & & $\begin{array}{c}-0.140 \\
(0.0972)\end{array}$ & $\begin{array}{c}-0.199^{*} \\
(0.105)\end{array}$ & & \\
\hline (ln) wage & & & & & & $\begin{array}{l}0.215 \\
(0.155)\end{array}$ & $\begin{array}{l}0.293^{*} \\
(0.163)\end{array}$ \\
\hline Observations & 1,500 & 1,164 & 1,164 & 1,164 & 1,164 & 1,164 & 1,164 \\
\hline R-squared & 0.552 & 0.580 & 0.580 & 0.570 & 0.571 & 0.432 & 0.334 \\
\hline Metropolitan FEs & yes & yes & yes & yes & yes & yes & yes \\
\hline Time FEs & yes & yes & yes & yes & yes & yes & yes \\
\hline widstat & 21.56 & 8.718 & 19.06 & 34.33 & 48.80 & 11.72 & 15.36 \\
\hline
\end{tabular}

Notes: The dependent variable is the net-in-migration rate. The independent variable is either (log) GDP per capita, unemployment rates or average wages in US metropolitan areas between 2005 and 2010, as indicated. (log) GDP per capita, unemployment rates or wages are instrumented with the interaction of a dummy for the post crisis period and the importance of construction, the debt to income ratio introduced in Mian and Sufi (2013), or interaction of a dummy for the post crisis period and the importance of construction, the debt to income ratio introduced in Mian and Sufi 2013 , or
the importance of the local aggregate demand, see more details in table 3 or in the text. Regressions are weighted by the number of observations used to compute the shares of construction. F-stats reported are the F-stats of excluded instruments in the first stage regression. Robust standard errors clustered at the metropolitan area level are reported. Number of observations: 250 metropolitan areas x 6 years $=1500$ or 194 metropolitan areas x 6 years $=1164$ when Mian and Sufi (2013) measure used. ${ }^{*} \mathrm{p}<.1,{ }^{* *} \mathrm{p}<.05$ and ${ }^{* * *} \mathrm{p}<.001$ 
Table 7: The migration response to the crisis: In-migration rates, total population

Panel A: In-migration rates

\begin{tabular}{|c|c|c|c|c|c|c|c|}
\hline VARIABLES & $\begin{array}{c}(1) \\
\text { In-migration } \\
\text { rate } \\
\text { IV1 }\end{array}$ & $\begin{array}{c}(2) \\
\text { In-migration } \\
\text { rate } \\
\text { IV2 }\end{array}$ & $\begin{array}{c}\text { (3) } \\
\text { In-migration } \\
\text { rate } \\
\text { IV3 } \\
\end{array}$ & $\begin{array}{c}\text { (4) } \\
\text { In-migration } \\
\text { rate } \\
\text { IV2 }\end{array}$ & $\begin{array}{c}(5) \\
\text { In-migration } \\
\text { rate } \\
\text { IV3 }\end{array}$ & $\begin{array}{c}(6) \\
\text { In-migration } \\
\text { rate } \\
\text { IV2 } \\
\end{array}$ & $\begin{array}{c}(7) \\
\text { In-migration } \\
\text { rate } \\
\text { IV3 }\end{array}$ \\
\hline (ln) per capita GDP & $\begin{array}{c}0.158^{* * *} \\
(0.0247)\end{array}$ & $\begin{array}{c}0.0852^{* * *} \\
(0.0289)\end{array}$ & $\begin{array}{c}0.104^{* * *} \\
(0.0238)\end{array}$ & & & & \\
\hline Unemployment rate & & & & $\begin{array}{c}-0.155^{* *} \\
(0.0648)\end{array}$ & $\begin{array}{c}-0.226^{* * *} \\
(0.0767)\end{array}$ & & \\
\hline (ln) wage & & & & & & $\begin{array}{c}0.238^{* *} \\
(0.110)\end{array}$ & $\begin{array}{c}0.333^{* * * *} \\
(0.124)\end{array}$ \\
\hline Observations & 1,500 & 1,164 & 1,164 & 1,164 & 1,164 & 1,164 & 1,164 \\
\hline R-squared & 0.858 & 0.890 & 0.886 & 0.892 & 0.890 & 0.809 & 0.735 \\
\hline Metropolitan FEs & yes & yes & yes & yes & yes & yes & yes \\
\hline Time FEs & yes & yes & yes & yes & yes & yes & yes \\
\hline widstat & 21.56 & 8.718 & 19.06 & 34.33 & 48.80 & 11.72 & 15.36 \\
\hline
\end{tabular}

Panel B: Out-migration rates

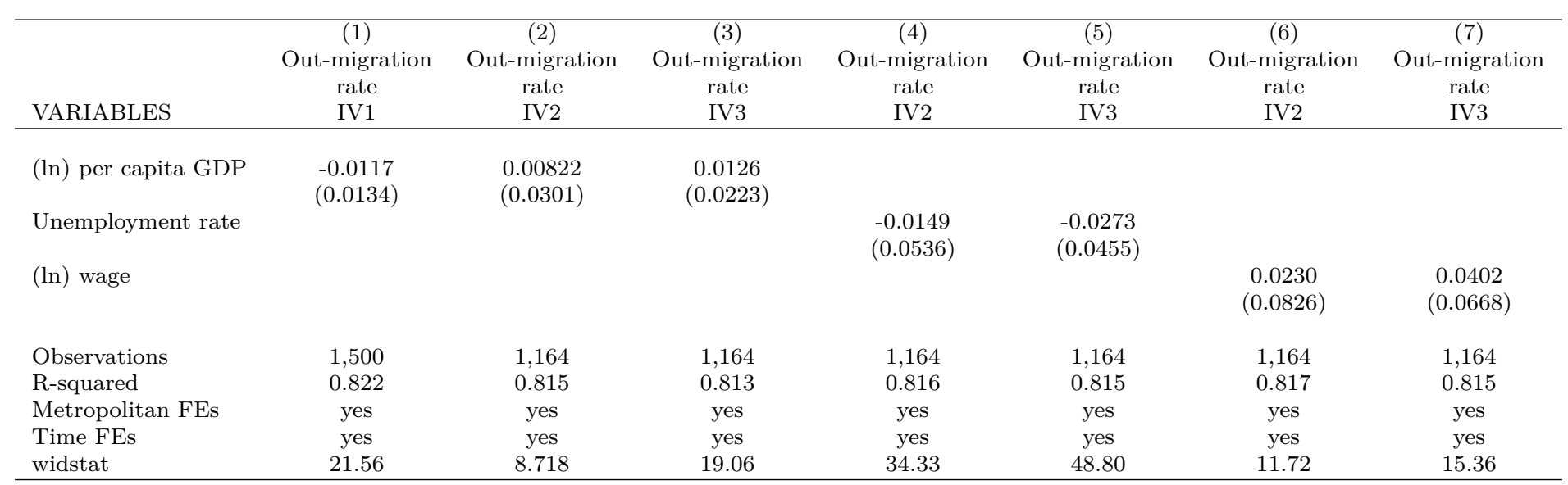

Notes: The dependent variable is the in-migration rate and the out-migration rate. The independent variable is either (log) GDP per capita, unemployment rates or average wages in US metropolitan areas between 2005 and 2010, as indicated. (log) GDP per capita, unemployment rates or wages are instrumented with the interaction of a dummy for the post crisis period and the importance of construction, the debt to income ratio introduced in Mian and Sufi (2013), or the importance of the local aggregate demand, see more details in table 3 or in the text. Regressions are weighted by the number of observations used to compute the shares of construction. F-stats reported are the F-stats of excluded instruments in the first stage regression. Robust standard errors clustered at the metropolitan area level are reported. Number of observations: 250 metropolitan areas $\mathrm{x}$ 6 years $=1500$ or 194 metropolitan areas x 6 years $=1164$ when Mian and Sufi (2013) measure used. ${ }^{*} \mathrm{p}<.1,{ }^{* *} \mathrm{p}<.05$ and ${ }^{* * *} \mathrm{p}<.001$. 
Table 8: The migration response to the crisis: In-migration rates, low-skilled population

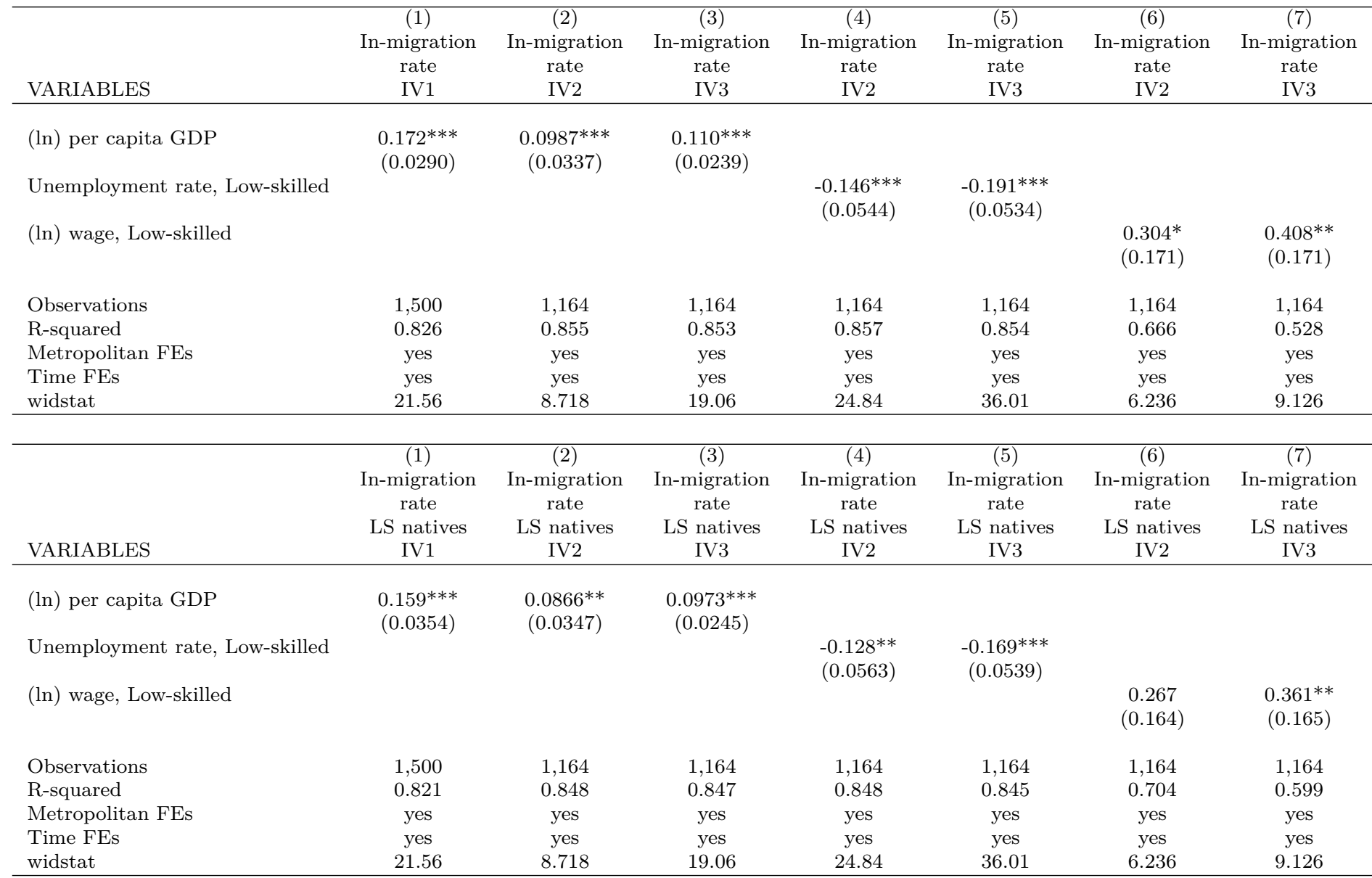

Notes: The dependent variable is the in-migration rate of low-skilled people. The independent variable is either (log) GDP per capita, unemployment rates or average wages in US metropolitan areas between 2005 and 2010. (log) GDP per capita, unemployment rates or wages are instrumented with the interaction of a dummy for the post crisis period and the importance of construction, the debt to income ratio introduced in Mian and Sufi (2013), or the importance of the local aggregate demand, see more details in table 3 or in the text. Regressions are weighted by the number of observations used to compute the shares of construction. F-stats reported are the F-stats of excluded instruments in the first stage regression. Robust standard errors clustered at the metropolitan area level are reported. Number of observations: 250 metropolitan areas x 6 years $=1500$ or 194 metropolitan areas x 6 years $=1164$ when Mian and Sufi $\left[2013\right.$, measure used. ${ }^{*} \mathrm{p}<.1,{ }^{* *} \mathrm{p}<.05$ and ${ }^{* * *} \mathrm{p}<.001$ 
Table 9: The migration response to the crisis: In-migration rates, high-skilled population

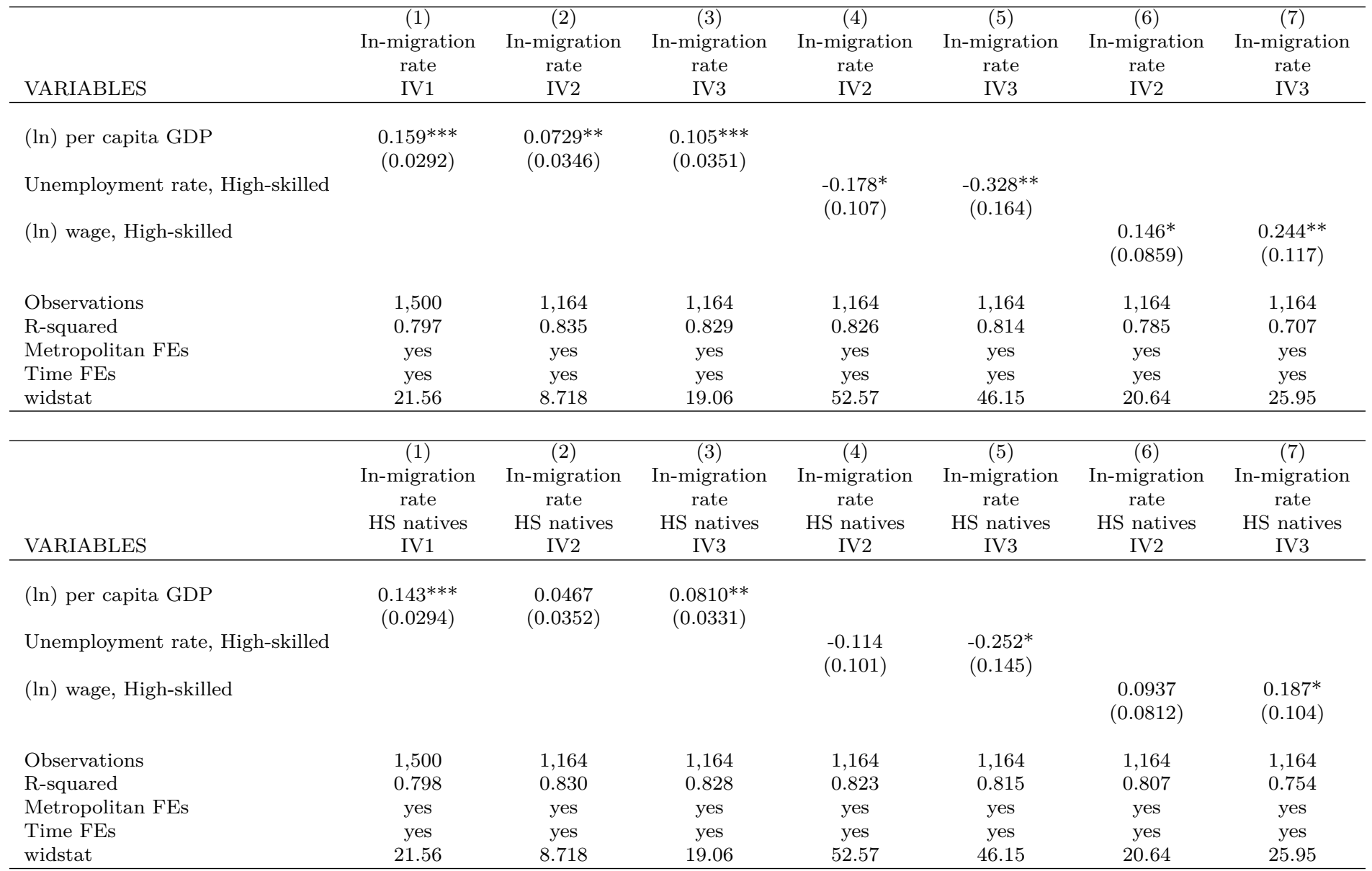

Notes: The dependent variable is the in-migration rate of high-skilled people. The independent variable is either (log) GDP per capita, unemployment rates or average wages in US metropolitan areas between 2005 and 2010. (log) GDP per capita, unemployment rates or wages are instrumented with the interaction of a dummy for the post crisis period and the importance of construction, the debt to income ratio introduced in Mian and Sufi (2013), or the importance of the local aggregate demand, see more details in table 3 or in the text. Regressions are weighted by the number of observations used to compute the shares of construction. F-stats reported are the F-stats of excluded instruments in the first stage

regression. Robust standard errors clustered at the metropolitan area level are reported. Number of observations: 250 metropolitan areas $\mathrm{x} 6$ years $=$ 1500 or 194 metropolitan areas x 6 years $=1164$ when Mian and Sufi (2013) measure used. ${ }^{*} \mathrm{p}<.1,{ }^{* *} \mathrm{p}<.05$ and ${ }^{* * *} \mathrm{p}<.001$. 
Table 10: In- migration, out-migration and population growth

Panel A: Census data, metropolitan-level variation

\begin{tabular}{|c|c|c|c|c|c|c|c|c|}
\hline VARIABLES & $\begin{array}{c}\text { (1) } \\
\text { In-migration } \\
\text { rate } \\
\text { OLS } \\
\end{array}$ & $\begin{array}{c}(2) \\
\text { Out-migration } \\
\text { rate } \\
\text { OLS } \\
\end{array}$ & $\begin{array}{c}(3) \\
\text { In-migration } \\
\text { rate } \\
\text { OLS } \\
\end{array}$ & $\begin{array}{c}(4) \\
\text { Out-migration } \\
\text { rate } \\
\text { OLS } \\
\end{array}$ & $\begin{array}{c}5) \\
\text { In-migration } \\
\text { rate } \\
\text { OLS } \\
\end{array}$ & $\begin{array}{c}(6) \\
\text { Out-migration } \\
\text { rate } \\
\text { OLS } \\
\end{array}$ & $\begin{array}{c}(7) \\
\text { In-migration } \\
\text { rate } \\
\text { OLS } \\
\end{array}$ & $\begin{array}{c}(8) \\
\text { Out-migration } \\
\text { rate } \\
\text { OLS } \\
\end{array}$ \\
\hline Population growth rate & $\begin{array}{c}0.903^{* * *} \\
(0.0609)\end{array}$ & $\begin{array}{l}-0.0969 \\
(0.0609)\end{array}$ & $\begin{array}{c}0.448^{* *} \\
(0.209)\end{array}$ & $\begin{array}{c}-0.552^{* * *} \\
(0.209)\end{array}$ & $\begin{array}{c}0.718^{* * * *} \\
(0.0929)\end{array}$ & $\begin{array}{c}-0.282^{* * *} \\
(0.0929)\end{array}$ & $\begin{array}{c}0.686^{* * *} \\
(0.156)\end{array}$ & $\begin{array}{c}-0.314^{* *} \\
(0.156)\end{array}$ \\
\hline $\begin{array}{l}\text { Observations } \\
\text { R-squared }\end{array}$ & $\begin{array}{c}474 \\
0.524 \\
\end{array}$ & $\begin{array}{c}474 \\
0.013 \\
\end{array}$ & $\begin{array}{c}474 \\
0.875 \\
\end{array}$ & $\begin{array}{c}474 \\
0.740 \\
\end{array}$ & $\begin{array}{c}474 \\
0.975 \\
\end{array}$ & $\begin{array}{c}474 \\
0.948 \\
\end{array}$ & $\begin{array}{c}474 \\
0.987\end{array}$ & $\begin{array}{c}474 \\
0.973 \\
\end{array}$ \\
\hline \multicolumn{9}{|c|}{ Panel B: Census data, state-level variation } \\
\hline Population growth rate & $\begin{array}{c}\text { In-migration } \\
\text { rate } \\
0.908^{* * *} \\
(0.00918)\end{array}$ & $\begin{array}{c}\text { Out-migration } \\
\text { rate } \\
-0.0920^{* * *} \\
(0.00918)\end{array}$ & $\begin{array}{c}\text { In-migration } \\
\text { rate } \\
0.905^{* * *} \\
(0.00978)\end{array}$ & $\begin{array}{c}\text { Out-migration } \\
\text { rate } \\
-0.0953^{* * *} \\
(0.00978)\end{array}$ & $\begin{array}{c}\text { In-migration } \\
\text { rate } \\
0.954^{* * *} \\
(0.0500)\end{array}$ & $\begin{array}{c}\text { Out-migration } \\
\text { rate } \\
-0.0455 \\
(0.0500)\end{array}$ & $\begin{array}{c}\text { In-migration } \\
\text { rate } \\
0.931^{* * *} \\
(0.0796)\end{array}$ & $\begin{array}{c}\text { Out-migration } \\
\text { rate } \\
-0.0686 \\
(0.0796)\end{array}$ \\
\hline $\begin{array}{l}\text { Observations } \\
\text { R-squared }\end{array}$ & $\begin{array}{c}204 \\
0.965 \\
\end{array}$ & $\begin{array}{c}204 \\
0.222 \\
\end{array}$ & $\begin{array}{c}204 \\
0.995 \\
\end{array}$ & $\begin{array}{c}204 \\
0.894 \\
\end{array}$ & $\begin{array}{c}204 \\
0.996 \\
\end{array}$ & $\begin{array}{c}204 \\
0.904 \\
\end{array}$ & $\begin{array}{c}204 \\
0.997 \\
\end{array}$ & $\begin{array}{c}204 \\
0.922 \\
\end{array}$ \\
\hline \multicolumn{9}{|c|}{ Panel C: CPS data, regional variation } \\
\hline Population growth rate & $\begin{array}{c}\text { In-migration } \\
\text { rate } \\
1.504^{* * *} \\
(0.114)\end{array}$ & $\begin{array}{c}\text { Out-migration } \\
\text { rate } \\
0.504^{* * *} \\
(0.114)\end{array}$ & $\begin{array}{c}\text { In-migration } \\
\text { rate } \\
1.151^{* * *} \\
(0.183)\end{array}$ & $\begin{array}{c}\text { Out-migration } \\
\text { rate } \\
0.151 \\
(0.183)\end{array}$ & $\begin{array}{c}\text { In-migration } \\
\text { rate } \\
0.738^{* * *} \\
(0.0784)\end{array}$ & $\begin{array}{c}\text { Out-migration } \\
\text { rate } \\
-0.262^{* * *} \\
(0.0784)\end{array}$ & $\begin{array}{c}\text { In-migration } \\
\text { rate } \\
0.622^{* * *} \\
(0.0426)\end{array}$ & $\begin{array}{c}\text { Out-migration } \\
\text { rate } \\
-0.378^{* * *} \\
(0.0426)\end{array}$ \\
\hline $\begin{array}{l}\text { Observations } \\
\text { R-squared }\end{array}$ & $\begin{array}{c}270 \\
0.471\end{array}$ & $\begin{array}{c}270 \\
0.091\end{array}$ & $\begin{array}{c}270 \\
0.557\end{array}$ & $\begin{array}{c}270 \\
0.238\end{array}$ & $\begin{array}{c}270 \\
0.934\end{array}$ & $\begin{array}{c}270 \\
0.886\end{array}$ & $\begin{array}{c}270 \\
0.978\end{array}$ & $\begin{array}{c}270 \\
0.963\end{array}$ \\
\hline State FEs & no & no & yes & yes & yes & yes & yes & yes \\
\hline Time FEs & no & no & no & no & yes & yes & yes & yes \\
\hline State trends & no & no & no & no & no & no & yes & yes \\
\hline
\end{tabular}

Notes: These regressions show the decomposition of population growth rates into in-migration rates and out-migration rates. The table shows 4 possible specifications, with various sets of fixed effects, that are presented in columns (1) and (2), (3) and (4), (5) and (6) and (7) and (8). Standard errors are clustered at the level of the geographic aggregation. Panel A, uses Census data at the metropolitan area between 1980 and 2000. Panel B, uses Census data at the state level between 1970 and 2000. Panel C, uses CPS data at the regional level between 1981 and $2012 .{ }^{*} \mathrm{p}<.1,{ }^{* *} \mathrm{p}<.05$ and $* * * \mathrm{p}<.001$. 
Table 11: Internal migration and population size

Panel A: Census data, metropolitan-level variation

\begin{tabular}{|c|c|c|c|c|c|c|c|c|}
\hline VARIABLES & $\begin{array}{l}\text { (1) } \\
\text { (ln) In } \\
\text { migrants } \\
\text { OLS }\end{array}$ & $\begin{array}{c}(2) \\
(\ln ) \text { In } \\
\text { migrants } \\
\text { OLS }\end{array}$ & $\begin{array}{l}(3) \\
\text { (ln) Out } \\
\text { migrants } \\
\text { OLS }\end{array}$ & $\begin{array}{l}(4) \\
\text { (ln) Out } \\
\text { migrants } \\
\text { OLS }\end{array}$ & $\begin{array}{l}(5) \\
\text { (ln) In } \\
\text { migrants } \\
\text { OLS }\end{array}$ & $\begin{array}{c}(6) \\
(\ln ) \text { In } \\
\text { migrants } \\
\text { OLS }\end{array}$ & $\begin{array}{l}(7) \\
\text { (ln) Out } \\
\text { migrants } \\
\text { OLS }\end{array}$ & $\begin{array}{l}(8) \\
\text { (ln) Out } \\
\text { migrants } \\
\text { OLS }\end{array}$ \\
\hline (ln) Population & $\begin{array}{c}0.854^{* * *} \\
(0.0406)\end{array}$ & $\begin{array}{c}0.919^{* * *} \\
(0.0355)\end{array}$ & $\begin{array}{c}0.922^{* * *} \\
(0.0182)\end{array}$ & $\begin{array}{c}0.908^{* * *} \\
(0.0172)\end{array}$ & $\begin{array}{c}0.849 * * * \\
(0.0391)\end{array}$ & $\begin{array}{c}0.891 * * * \\
(0.0351)\end{array}$ & $\begin{array}{c}0.920 * * * \\
(0.0174)\end{array}$ & $\begin{array}{c}0.878^{* * *} \\
(0.0177)\end{array}$ \\
\hline Observations & 474 & 474 & 474 & 474 & 474 & 474 & 474 & 474 \\
\hline R-squared & 0.821 & 0.732 & 0.931 & 0.805 & 0.859 & 0.818 & 0.964 & 0.929 \\
\hline Time FEs & no & no & no & no & yes & yes & yes & yes \\
\hline Weights & yes & no & yes & no & yes & no & yes & no \\
\hline \multicolumn{9}{|c|}{ Panel B: Census data, state-level variation } \\
\hline VARIABLES & $\begin{array}{c}(1) \\
(\ln ) \text { In } \\
\text { migrants } \\
\text { OLS }\end{array}$ & $\begin{array}{c}(2) \\
(\ln ) \text { In } \\
\text { migrants } \\
\text { OLS }\end{array}$ & $\begin{array}{c}(3) \\
\text { (ln) Out } \\
\text { migrants } \\
\text { OLS }\end{array}$ & $\begin{array}{l}(4) \\
\text { (ln) Out } \\
\text { migrants } \\
\text { OLS }\end{array}$ & $\begin{array}{c}(5) \\
(\ln ) \text { In } \\
\text { migrants } \\
\text { OLS }\end{array}$ & $\begin{array}{c}(6) \\
(\ln ) \text { In } \\
\text { migrants } \\
\text { OLS }\end{array}$ & $\begin{array}{c}(7) \\
\text { (ln) Out } \\
\text { migrants } \\
\text { OLS }\end{array}$ & $\begin{array}{c}\text { (8) } \\
\text { (ln) Out } \\
\text { migrants } \\
\text { OLS }\end{array}$ \\
\hline (ln) Population & $\begin{array}{c}0.879^{* * *} \\
(0.0264)\end{array}$ & $\begin{array}{c}0.864^{* * *} \\
(0.0291)\end{array}$ & $\begin{array}{c}0.859^{* * *} \\
(0.0222)\end{array}$ & $\begin{array}{c}0.756^{* * *} \\
(0.0307)\end{array}$ & $\begin{array}{c}0.917^{* * *} \\
(0.0293)\end{array}$ & $\begin{array}{c}0.864^{* * *} \\
(0.0300)\end{array}$ & $\begin{array}{c}0.830^{* * *} \\
(0.0230)\end{array}$ & $\begin{array}{c}0.752^{* * *} \\
(0.0314)\end{array}$ \\
\hline Observations & 204 & 204 & 204 & 204 & 204 & 204 & 204 & 204 \\
\hline R-squared & 0.723 & 0.799 & 0.836 & 0.824 & 0.922 & 0.925 & 0.959 & 0.941 \\
\hline Time FEs & no & no & no & no & yes & yes & yes & yes \\
\hline Weights & yes & no & yes & no & yes & no & yes & no \\
\hline
\end{tabular}

Notes: These regressions show the relationship between internal migration and population size. Standard errors are clustered at the level of the geographic aggregation. Panel A, uses Census data at the metropolitan area between 1980 and 2000. Panel B, uses Census data at the state level between 1970 and $2000 .{ }^{*} \mathrm{p}<.1, * * \mathrm{p}<.05$ and $* * * \mathrm{p}<.001$ for whether the coefficient is smaller than 1. 
Table 12: Comparison between the counterfactual and the predicted values by the model

\begin{tabular}{lcccc}
\hline & $\begin{array}{c}(1) \\
\text { Wage }\end{array}$ & $\begin{array}{c}(2) \\
\text { Labor } \\
\text { OLS }\end{array}$ & $\begin{array}{c}(3) \\
\text { Wage } \\
\text { OLS }\end{array}$ & $\begin{array}{c}\text { Labor } \\
\text { OLS }\end{array}$ \\
\hline VARIABLES & & & & \\
Wage predicted by model & $-0.759^{*}$ & & $-2.554^{* * *}$ & \\
& $(0.444)$ & & \\
Population predicted by model & & $0.482^{*}$ & & $0.547^{* * *}$ \\
& & $(0.249)$ & & $(0.202)$ \\
Observations & & & & \\
R-squared & 1,315 & 1,315 & 1,315 & 1,315 \\
Time FEs & 0.980 & 1.000 & 0.412 & 0.486 \\
Metropolitan FEs & yes & yes & yes & yes \\
First Difference & yes & yes & & yes \\
\hline
\end{tabular}

Notes: This table shows the elasticities between the average wage and population levels predicted by the model and in the data, for the years at which the model is not calibrated, i.e. from 2006 onwards. Robust standard errors clustered at the metropolitan area are reported. ${ }^{*} \mathrm{p}<.1,{ }^{* *} \mathrm{p}<.05$ and ${ }^{* * *} \mathrm{p}<.001$. 


\section{Theory Appendix}

\subsection{Labor market with unemployment}

The local labor market equilibrium is determined by a search and match technology that takes place in each market (Pissarides, 2000).

Again, I simplify the intuitions by assuming standard functional forms of the various key variables. The constant returns to scale matching function is given by $m\left(u_{m}, v_{m}\right)=u_{m}^{\eta} v_{m}^{1-\eta} \cdot u_{c}$ is the unemployment rate, $v_{c}$ is the vacancy rate. The probability of job loss is exogenous and given by $\delta$. The revenue flow per worker is given by the expression $r_{m}=p_{m}\left(1-\theta_{m}\right) B_{m} Q_{m}^{\frac{1}{\sigma}} L_{c}^{-\frac{1}{\sigma}}$. Importantly, the fixed factor ensures that the revenue flow per worker is smaller when there are more workers in the local economy, other things equal. The cost flow per vacancy is, like in the rest of the literature, given by $r_{m} f$. Finally the unemployment benefits are specific to each location and given by $b_{m}$. I further assume that they are proportional to current wages $b_{m}=\tau_{m} w_{m}$.

In these conditions, we have the following three equilibrium conditions (before relocation across labor markets takes place):

Beveridge curve

The fact that in equilibrium, unemployment growth is 0 implies:

$$
\delta\left(1-u_{m}\right)=u_{m}^{\eta} v_{m}^{1-\eta}
$$

So:

$$
u_{m}=\frac{\delta}{\delta+\theta_{m}^{1+\eta}}
$$

where $\theta_{m}=v_{m} / u_{m}$ is the labor market tightness.

Job creation

The zero profit condition determines the job creation equation:

$$
r_{m}-w_{m}-\frac{\left(i_{m}+\delta\right) r_{m} f}{\theta_{m}^{\eta}}=0
$$

Wage curve 
Nash bargaining between firms and workers (with weight $\beta$ ) implies:

$$
w_{m}=(1-\beta) b_{m}+\beta r_{m}\left(1+f \theta_{m}\right)
$$

These 3 equations determine $\left\{u_{m}, \theta_{m}, w_{m}\right\}$ in each local labor market.

\subsection{Location Choice with Unemployment}

The indirect utility of the workers is given by the local wage $w_{m^{\prime}}$ and unemployment rate $u_{m^{\prime}}$, the amenities $A_{m^{\prime}}$ and the idiosyncratic draw they get for location $m^{\prime}$, given that they live in $m$ :

$$
v_{m^{\prime}}^{i}=\ln V_{m^{\prime}}+\epsilon_{m, m^{\prime}}^{i}=\ln A_{m^{\prime}}+\ln \left(\left(1-u_{m^{\prime}}\right) * \omega_{m^{\prime}}+u_{m^{\prime}} * b_{m^{\prime}}\right)+\epsilon_{m, m^{\prime}}^{i}
$$

where $u_{m^{\prime}}, b_{m^{\prime}}$ and $\omega_{m^{\prime}}$ are the unemployment rate, unemployment benefits and wages in region $m^{\prime}$, respectively. The intuition is straightforward. If an individual $i$ moves to $m^{\prime}$, the probability that she will be unemployed is $u_{m^{\prime}}$. She will then receive the unemployment benefit $b_{m^{\prime}}$. Meanwhile, the probability that she will be employed and receive the wage $\omega_{m^{\prime}}$ is $1-u_{m^{\prime}}$.

This expression can be simplified even further by using the assumption that unemployment benefits are proportional to wages $b_{m^{\prime}}=\tau_{m^{\prime}} w_{m^{\prime}}$ then we have

$v_{m^{\prime}}^{i}=\ln A_{m^{\prime}}+\ln \left(\left(1-u_{m^{\prime}}\right) * w_{m^{\prime}}+u_{m^{\prime}} * \tau_{m^{\prime}} w_{m^{\prime}}\right)+\epsilon_{m, m^{\prime}}^{i} \approx \ln A_{m^{\prime}}+\ln w_{m^{\prime}}-u_{m^{\prime}}\left(1-\tau_{m^{\prime}}\right)+\epsilon_{m, m^{\prime}}^{i}=\ln V_{m^{\prime}}+\epsilon_{m, m^{\prime}}^{i}$

This expression has a simple interpretation. Indirect utility is higher if amenities are higher, (ln) wages are higher and unemployment rates are lower - the more this is the case, the lower unemployment benefits are.

Note that the indirect utility has a common component to all workers $\ln V_{m^{\prime}}$ that depends on variables at destination and an idiosyncratic component $\epsilon_{m, m^{\prime}}^{i}$ specific to each worker. It is also important to note that workers decide on future location given the current wages across locations. This is an optimal behavior if two things hold. First, workers do not expect shocks to happen in any location in the future. Second, workers do not form expectations about how many people will move to each location (Kennan and Walker, 2011).

Thus, workers maximize:

$$
\max _{s^{\prime} \in M}\left\{\ln V_{m^{\prime}}+\epsilon_{m, m^{\prime}}^{i}\right\}
$$

The general solution to this maximization problem gives the probability that an individual $i$ 
residing in a location $m$ moves to $m^{\prime}$, given current wages and valuations of amenities $\mathbf{A}, \mathbf{w}, \mathbf{u}, 32$

$$
p_{m, m^{\prime}}^{i}=p_{m, m^{\prime}}(\mathbf{A}, \mathbf{w}, \mathbf{u})
$$

This idiosyncratic taste shock shapes the flows of workers across locations, as I discuss in detail in the paper.

By the law of large numbers we can then use equation (4) to obtain the flow of people between $m$ and $m^{\prime}$ :

$$
P_{m, m^{\prime}}=p_{m, m^{\prime}}^{i} * N_{m} \text { for } s \neq s^{\prime}
$$

where $N_{m}$ is the population residing in $m$. Note that this defines a matrix that represents the flows of people between any two locations in the economy.

\subsection{Equilibrium with Unemployment}

The definition of the equilibrium has two parts. I start by defining the equilibrium in the short run. It satisfies two conditions. First, firms take as given the productivity $B_{m}$, the productivity of each factor $\theta_{m}$ and factor prices in each location to maximize profits. Second, labor markets clear in each location. This equates the supply and the demand for labor and determines the wage in every local labor market. More formally:

Definition III. A short-run equilibrium is defined by the following decisions:

- Given $\left\{\theta_{m}, B_{m}, K_{m}, \sigma, w_{m}, r_{m}\right\}_{m \in M}$ firms maximize profits.

- Labor and land markets clear in each $s \in M$ so that $\left\{w_{m}, u_{m}, \theta_{m}, r_{m}\right\}$ is determined.

Note that in the short run, the two factors of production are fixed. At the end of the period relocation takes place which determines the distribution of workers across space in the following period. We can define the long-run equilibrium by adding an extra condition to the short-run definition. In words, I say that the economy is in long-run equilibrium when bilateral flows of people are equalized across regions. More specifically,

Definition IV. Given $\left\{\theta_{m}, B_{m}, K_{m}, \sigma, A_{m}\right\}_{m \in M}$, a long-run equilibrium is defined as a short-run equilibrium with equalized bilateral flows of population across locations. This is:

$$
P_{m, m^{\prime}}=P_{m^{\prime}, m}, \forall m, m^{\prime} \in M
$$

where the flows are determined by the location maximization problem introduced before.

\footnotetext{
${ }^{32}$ I use bold letters to denote the vector of all the locations in the economy.
} 


\subsection{Proof of lemma 1}

In what follows I proof lemma 1 .

Proof. For equation 12 .

$$
\ln P_{j, m}=\ln N_{j}+\frac{1}{\gamma} \ln V_{-j}-\ln \left(V_{-j}^{1 / \gamma}+V_{j}^{1 / \gamma}\right)+\frac{1}{\lambda} \ln V_{m}-\ln \sum_{l \in M} V_{l}^{1 / \lambda}
$$

Let's find the derivative with respect to each of these terms 33

$$
\frac{\partial \ln V_{-j}}{\partial \ln w_{m}}=\lambda \frac{\partial \ln \sum_{l \in M} V_{l}^{1 / \lambda}}{\partial \ln w_{m}}=\lambda \frac{1}{\sum_{l \in M} V_{l}^{1 / \lambda}} \sum_{l \in M} \frac{1}{\lambda} V_{l}^{1 / \lambda} \frac{\partial \ln V_{l}}{\partial \ln w_{m}}=\frac{V_{m}^{1 / \lambda}}{\sum_{l \in M} V_{l}^{1 / \lambda}}
$$

The second term's derivative is:

$$
\begin{gathered}
\frac{\partial \ln \left(V_{-j}^{1 / \gamma}+V_{j}^{1 / \gamma}\right)}{\partial \ln w_{m}}=\frac{1}{\gamma} \frac{1}{V_{j}^{1 / \gamma}+V_{-j}^{1 / \gamma}}\left(V_{-j}^{1 / \gamma} \frac{\partial \ln V_{-j}}{\partial \ln w_{m}}+V_{j}^{1 / \gamma} \frac{\partial \ln V_{j}}{\partial \ln w_{m}}\right)= \\
=\frac{1}{\gamma} \frac{V_{-j}^{1 / \gamma}}{V_{j}^{1 / \gamma}+V_{-j}^{1 / \gamma}} \frac{V_{m}^{1 / \lambda}}{\sum_{l \in M} V_{l}^{1 / \lambda}}=\frac{1}{\gamma} \eta_{j} \frac{V_{m}^{1 / \lambda}}{\sum_{l \in M} V_{l}^{1 / \lambda}}
\end{gathered}
$$

The third term is simple:

$$
\frac{\partial \ln V_{m}}{\partial \ln w_{m}}=1
$$

While the fourth term is:

$$
\begin{gathered}
\frac{\partial \ln \sum_{l \in M} V_{l}^{1 / \lambda}}{\partial \ln w_{m}}=\frac{1}{\sum_{l \in M} V_{l}^{1 / \lambda}} \sum_{l \in M} \frac{1}{\lambda} V_{l}^{1 / \lambda-1} \frac{\partial V_{l}}{\partial \ln w_{m}}= \\
=\frac{1}{\lambda} \frac{1}{\sum_{l \in M} V_{l}^{1 / \lambda}} \sum_{l \in M} V_{l}^{1 / \lambda} \frac{\partial \ln V_{l}}{\partial \ln w_{m}}=\frac{1}{\lambda} \frac{V_{m}^{1 / \lambda}}{\sum_{l \in M} V_{l}^{1 / \lambda}}
\end{gathered}
$$

Thus,

$$
\frac{\partial \ln P_{j, m}}{\partial \ln w_{m}}=\frac{1}{\lambda}-\frac{1}{\lambda} \frac{V_{m}^{1 / \lambda}}{\sum_{l \in M} V_{l}^{1 / \lambda}}+\frac{1}{\gamma} \frac{V_{m}^{1 / \gamma}}{\sum_{l \in M} V_{l}^{1 / \gamma}}-\frac{1}{\gamma} \eta_{j} \frac{V_{m}^{1 / \lambda}}{\sum_{l \in M} V_{l}^{1 / \lambda}}
$$

${ }^{33}$ So we now need to know $\frac{\partial \ln V_{j}}{\partial \ln w_{m}}$, starting from $\ln V_{m^{\prime}}=\ln A_{m^{\prime}}+\ln w_{m^{\prime}}$. This is:

$$
\frac{\partial \ln V_{m}}{\partial \ln w_{m}}=1
$$

Note also that $\frac{\partial \ln V_{j}}{\partial \ln w_{m}}=0$ if $j \neq m$. 
And,

$$
\frac{\partial \ln P_{j, m}}{\partial \ln w_{m}} \rightarrow \frac{1}{\lambda}
$$

For equation 13

$$
\ln P_{m, m}=\ln N_{m}+\frac{1}{\gamma} \ln V_{-m}-\ln \left(V_{-m}^{1 / \gamma}+V_{m}^{1 / \gamma}\right)+\frac{1}{\lambda} \ln V_{m}-\ln \sum_{l \in M} V_{l}^{1 / \lambda}
$$

Let's find the derivative with respect to each of these terms. For the first:

$$
\frac{\partial \ln V_{-m}}{\partial \ln w_{m}}=\lambda \frac{\partial \ln \sum_{l \in M} V_{l}^{1 / \lambda}}{\partial \ln w_{m}}=\lambda \frac{1}{\sum_{l \in M} V_{l}^{1 / \lambda}} \sum_{l \in M} \frac{1}{\lambda} V_{l}^{1 / \lambda} \frac{\partial \ln V_{l}}{\partial \ln w_{m}}=\frac{V_{m}^{1 / \lambda}}{\sum_{l \in M} V_{l}^{1 / \lambda}}
$$

The second term's derivative does change:

$$
\begin{gathered}
\frac{\partial \ln \left(V_{-m}^{1 / \gamma}+V_{m}^{1 / \gamma}\right)}{\partial \ln w_{m}}=\frac{1}{\gamma} \frac{1}{V_{m}^{1 / \gamma}+V_{-m}^{1 / \gamma}}\left(V_{-m}^{1 / \gamma} \frac{\partial \ln V_{-m}}{\partial \ln w_{m}}+V_{m}^{1 / \gamma} \frac{\partial \ln V_{m}}{\partial \ln w_{m}}\right)= \\
=\frac{1}{\gamma} \frac{V_{-m}}{V_{m}^{1 / \gamma}+V_{-m}^{1 / \gamma}} \frac{V_{m}^{1 / \lambda}}{\sum_{l \in M} V_{l}^{1 / \lambda}}+\frac{1}{\gamma} \frac{V_{m}^{1 / \gamma}}{V_{m}^{1 / \gamma}+V_{-m}^{1 / \gamma}}=\frac{1}{\gamma} \eta_{m} \frac{V_{m}^{1 / \lambda}}{\sum_{l \in M} V_{l}^{1 / \lambda}}+\frac{1}{\gamma} \frac{V_{m}^{1 / \gamma}}{V_{m}^{1 / \gamma}+V_{-m}^{1 / \gamma}}
\end{gathered}
$$

The third and fourth terms obviously do not change. Thus,

$$
\begin{gathered}
\frac{\partial \ln P_{m, m}}{\partial \ln w_{m}}=\frac{1}{\lambda}-\frac{1}{\lambda} \frac{V_{m}^{1 / \lambda}}{\sum_{l \in M} V_{l}^{1 / \lambda}}+\frac{1}{\gamma} \frac{V_{m}^{1 / \lambda}}{\sum_{l \in M} V_{l}^{1 / \lambda}}-\frac{1}{\gamma} \eta_{j} \frac{V_{m}^{1 / \lambda}}{\sum_{l \in M} V_{l}^{1 / \lambda}}-\frac{1}{\gamma} \frac{V_{m}^{1 / \gamma}}{V_{m}^{1 / \gamma}+V_{-m}^{1 / \gamma}} \\
\frac{\partial \ln P_{m, m}}{\partial \ln w_{m}} \rightarrow \frac{1}{\lambda}-\frac{1}{\gamma}\left(1-\eta_{m}\right)
\end{gathered}
$$

For equation 14

$$
\ln P_{j, m}=\ln N_{j}+\frac{1}{\gamma} \ln V_{-j}-\ln \left(V_{-j}^{1 / \gamma}+V_{j}^{1 / \gamma}\right)+\frac{1}{\lambda} \ln V_{m}-\ln \sum_{l \in M} V_{l}^{1 / \lambda}
$$

Let's find the derivative with respect to each of these terms:

$$
\frac{\partial \ln V_{-j}}{\partial \ln w_{j}}=\frac{V_{j}^{1 / \lambda}}{\sum_{l \in M} V_{l}^{1 / \lambda}}
$$


The second term's derivative is:

$$
\frac{\partial \ln \left(V_{-j}^{1 / \gamma}+V_{j}^{1 / \gamma}\right)}{\partial \ln w_{j}}=\frac{1}{\gamma} \eta_{j} \frac{V_{j}^{1 / \lambda}}{\sum_{l \in M} V_{l}^{1 / \lambda}}+\frac{1}{\gamma} \frac{V_{j}^{1 / \gamma}}{V_{m}^{1 / \gamma}+V_{-m}^{1 / \gamma}}
$$

The third term is simple:

$$
\frac{\partial \ln V_{m}}{\partial \ln w_{j}}=0
$$

While the fourth term is:

$$
\frac{\partial \ln \sum_{l \in M} V_{l}^{1 / \lambda}}{\partial \ln w_{j}}=\frac{1}{\lambda} \frac{V_{j}^{1 / \lambda}}{\sum_{l \in M} V_{l}^{1 / \lambda}}
$$

Thus,

$$
\frac{\partial \ln P_{j, m}}{\partial \ln w_{j}}=-\frac{1}{\lambda} \frac{V_{j}^{1 / \lambda}}{\sum_{l \in M} V_{l}^{1 / \lambda}}+\frac{1}{\gamma} \frac{V_{j}^{1 / \lambda}}{\sum_{l \in M} V_{l}^{1 / \lambda}}-\frac{1}{\gamma} \eta_{j} \frac{V_{j}^{1 / \lambda}}{\sum_{l \in M} V_{l}^{1 / \lambda}}-\frac{1}{\gamma}\left(1-\eta_{j}\right)
$$

and

$$
\frac{\partial \ln P_{j, m}}{\partial \ln w_{j}} \rightarrow-\frac{1}{\gamma}\left(1-\eta_{j}\right)
$$

For equation 15

$$
\ln P_{j, m}=\ln N_{j}+\frac{1}{\gamma} \ln V_{-j}-\ln \left(V_{-j}^{1 / \gamma}+V_{j}^{1 / \gamma}\right)+\frac{1}{\lambda} \ln V_{m}-\ln \sum_{l \in M} V_{l}^{1 / \lambda}
$$

Let's find the derivative with respect to each of these terms:

$$
\frac{\partial \ln V_{-j}}{\partial \ln w_{m^{\prime}}}=\frac{V_{m^{\prime}}^{1 / \lambda}}{\sum_{l \in M} V_{l}^{1 / \lambda}}
$$

The second term's derivative is:

$$
\frac{\partial \ln \left(V_{-j}^{1 / \gamma}+V_{j}^{1 / \gamma}\right)}{\partial \ln w_{m^{\prime}}}=\frac{1}{\gamma} \eta_{j} \frac{V_{m^{\prime}}^{1 / \lambda}}{\sum_{l \in M} V_{l}^{1 / \lambda}}
$$

The third term is simple:

$$
\frac{\partial \ln V_{m}}{\partial \ln w_{m^{\prime}}}=0
$$


While the fourth term is:

$$
\frac{\partial \ln \sum_{l \in M} V_{l}^{1 / \lambda}}{\partial \ln w_{m}}=\frac{1}{\lambda} \frac{V_{m^{\prime}}^{1 / \lambda}}{\sum_{l \in M} V_{l}^{1 / \lambda}}
$$

Thus,

$$
\frac{\partial \ln P_{j, m}}{\partial \ln w_{m^{\prime}}}=-\frac{1}{\lambda} \frac{V_{m^{\prime}}^{1 / \lambda}}{\sum_{l \in M} V_{l}^{1 / \lambda}}+\frac{1}{\gamma} \frac{V_{m^{\prime}}^{1 / \lambda}}{\sum_{l \in M} V_{l}^{1 / \lambda}}-\frac{1}{\gamma} \eta_{j} \frac{V_{m^{\prime}}^{1 / \lambda}}{\sum_{l \in M} V_{l}^{1 / \lambda}}
$$

and

$$
\frac{\partial \ln P_{j, m}}{\partial \ln w_{m^{\prime}}} \rightarrow 0
$$

\subsection{Proof of proposition 2}

Proof. From $N_{m}^{\prime}=\sum_{j \in M} P_{j, s}$ we obtain ${ }^{34}$

$\frac{\partial \ln N_{m}^{\prime}}{\partial \ln w_{m}}=\frac{1}{\sum_{j \in M} P_{j, m}} \sum_{j \in M} \frac{\partial P_{j, m}}{\partial \ln w_{m}}=\frac{1}{\sum_{j \in M} P_{j, m}} \sum_{j \in M} P_{j, m} \frac{\partial \ln P_{j, m}}{\partial \ln w_{m}}=\sum_{j \in M} \frac{P_{j, m}}{\sum_{j \in M} P_{j, m}} \frac{\partial \ln P_{j, m}}{\partial \ln w_{m}}$

Now, using lemma 1

$$
\frac{\partial \ln N_{m}^{\prime}}{\partial \ln w_{m}}=\sum_{j \in M} \frac{P_{j, m}}{\sum_{j \in M} P_{j, m}} \frac{\partial \ln P_{j, m}}{\partial \ln w_{m}} \rightarrow \frac{1}{\lambda}-\frac{P_{m, m}}{\sum_{l} P_{l, m}} \frac{1}{\gamma}\left(1-\eta_{m}\right)
$$

For the second part of the proposition,

From $N_{m}^{\prime}=\sum_{j \in M} P_{j, m}$ we obtain:

$$
\frac{\partial \ln N_{m}^{\prime}}{\partial \ln w_{m^{\prime}}}=\sum_{j \in M} \frac{P_{j, m}}{\sum_{j \in M} P_{j, m}} \frac{\partial \ln P_{j, m}}{\partial \ln w_{m^{\prime}}}
$$

Now, again using lemma 1

$$
\frac{\partial \ln N_{m}^{\prime}}{\partial \ln w_{m^{\prime}}} \rightarrow-\frac{1}{\gamma}\left(1-\eta_{m^{\prime}}\right)
$$

\footnotetext{
${ }^{34}$ Throughout it is useful to note that $\frac{\partial \ln y}{\partial x}=\frac{1}{y} \frac{\partial y}{\partial x}$
} 


\subsection{Proof of proposition 3}

Proof. From $I_{m}=\sum_{j \neq s} P_{j, s}$ we obtain:

$$
\frac{\partial \ln I_{m}}{\partial \ln w_{m}}=\frac{1}{\sum_{j \neq m} P_{j, m}} \sum_{j \neq m} \frac{\partial P_{j, m}}{\partial \ln w_{m}}=\frac{1}{\sum_{j \neq m} P_{j, m}} \sum_{j \neq m} P_{j, m} \frac{\partial \ln P_{j, m}}{\partial \ln w_{m}}
$$

So, we need to know $\frac{\partial \ln P_{j, m}}{\partial \ln w_{m}}$, which we know from lemma 1 .

$$
\frac{\partial \ln I_{m}}{\partial \ln w_{m}} \rightarrow \frac{1}{\lambda}
$$

Similarly, from $O_{m}=\sum_{j \neq m} P_{m, j}$ we obtain:

$$
\frac{\partial \ln O_{m}}{\partial \ln w_{m}}=\frac{1}{\sum_{j \neq m} P_{m, j}} \sum_{j \neq m} \frac{\partial P_{m, j}}{\partial \ln w_{m}}=\frac{1}{\sum_{j \neq m} P_{m, j}} \sum_{j \neq m} P_{m, j} \frac{\partial \ln P_{m, j}}{\partial \ln w_{m}}
$$

Again, using lemma 1

$$
\frac{\partial \ln P_{s, j}}{\partial \ln w_{m}} \rightarrow-\frac{1}{\gamma}\left(1-\eta_{m}\right)
$$

\subsection{Proof of corollary 4}

Proof. We only need to realize that:

$$
\frac{\partial\left(I_{m} / N_{m}\right)}{\partial \ln w_{m}}=\frac{\partial I_{m}}{N_{m} \partial \ln w_{m}}=\frac{I_{m}}{N_{m}} \frac{\partial \ln I_{m}}{\partial \ln w_{s}}
$$

The out-migration rate is analogous.

\subsection{Proof of proposition 5}

Proof. This is a consequence of:

$$
\frac{\partial \ln w_{m}}{\partial \ln N_{m}}=-\frac{1}{\sigma}\left(1-\frac{1}{Q_{m}^{\frac{\sigma-1}{\sigma}} N_{m}^{\frac{1}{\sigma}}}\right)<0
$$

\subsection{Proof of proposition 6}

Proof. The law of motion of the economy is given by: 


$$
N_{t+1}^{\prime}=N_{t} \times P_{t}
$$

where $P_{t}$ is the matrix of bilateral flows at time $t$.

Given an initial distribution of people across space $\left(N_{0}\right)$, we can easily compute the long-run equilibrium. 